\title{
THE MAJOR SPINAL AFFERENT SYSTEMS TO THE CEREBELLUM AND THE CEREBELLAR CORTICONUCLEAR CONNECTIONS IN MACACA MULATTA ${ }^{1}$
}

\author{
BHUKET VACHANANDA * \\ Laboratory of Comparative Neurology, Department of Anatomy, \\ Cniversity of Michigan \\ TWENTY FIGURES \\ INTRODUCTION
}

A remarkable degree of functional localization on the cerebellum has been revealed by using electrophysiologic studies but these findings have not as yet been documented satisfactorily by anatomical methods. The present investigation is concerned primarily with the topographic patterns within the major spinal afferent systems to the cerebellum and those in the cerebellar corticonuclear connections in Macaca mulatta.

\section{MATERIAL AND METHODS}

Eleven normal, young adult macaque monkeys (Macaca mulatta) of both sexes, weighing between $2.0 \mathrm{~kg}$ and $5.5 \mathrm{~kg}$, were used in this investigation. A variety of lesions was made in the spinal cord, the medulla oblongata and the cerebellum under open drop ether anesthesia and aseptic precautions. Different operations were performed on the animals according to the regions of the central nervous system concerned.

For the spinal cord lesions, laminectomies, usually involving one to two spinal laminae, were followed by longitudinal slit-

${ }^{1}$ Accepted in partial fulfilment of the requirements for the degree of Doctor of Philosophy at the University of Michigan.

2 The permanent address of the author is Department of Anatomy, Siriraj Hospjtal and Medical School, University of Medical Scienees, Bangkok, Thailand. 
ting of the dura, after which cordotomies or spinocerebellar tractotomies were made at different levels by direct cut or by electrical cauterization. In approaching the medulla or the inferior cerebellar region, suboccipital craniectomies of varying size were combined with the removal of the one or two uppermost cervical spinal laminae. After dural incisions, lesions were produced on the gracile tubercle, cuneate tubercle or the inferior aspect of the cerebellum by direct excision or by electrical means. A transtentorial approach was used in exposing the superior surface of the cerebellum. This procedure included a unilateral occipitoparietal craniectomy of varying size, excision of the occipital pole of the cerebral hemisphere and division of the tentorium cerebelli. Any hemorrhage was effectively controlled with electrocautery and gelfoam.

In order to produce a lesion by electrical fulguration, a galvanic current of 3 ma was usually employed for 60 seconds. Before making a lesion, the cerebellar cortex was stimulated by a threshold faradic current of 40 cycle frequency and 1 msec. pulse duration. The strength of the current varied between 3 to 6 volts. A Grass stimulator, Model 3C, was used for these purposes. Then a cortical lesion was produced on a selected area where a somatotopical response had been revealed. Cotton swabs were usually employed to enlarge the cortical lesion to a desired size. In all cases the dural incisions were closed, whenever possible, and the muscular and fascial layers were tightly approximated in anatomical relations to provide protection before suturing the skin. One week after the first operation another operation was performed on some of the monkeys. In each case the animal made an uneventful recovery from the operation.

Several times during the postoperative period the animals were examined neurologically. They were then sacrificed, usually two weeks after the last operation. Then the animals, anesthetized with ether inhalation or a large dose of evipal injected intraperitoneally, were perfused through their arterial systems with $800-1000 \mathrm{~cm}^{3}$ of $10 \%$ formalin. The brain 
and the spinal cord were removed with great care. The cerebellum, the brainstem, the upper cervical cord and, in some cases, lower levels of the cord were prepared by the Swank and Davenport ('35) modification of the Marchi technique, which visualizes only the degenerating myelinated fibers. The experimental material was cut transversely in serial sections of $50 \mu$ thickness and every second section was mounted. Some of the cerebella were sectioned serially in sagittal plane for more accurate determination of the fibers projecting to the cerebellar subdivisions.

In order to interpret the fiber distribution on the cerebellum, both the estimated amount of the fibers entering each cerebellar subdivision and the relative cortical area of destination within that subdivision have been determined. Gross specimens of the cerebellum were used as references in determining

TABLE 1

General scheme of the mammalian cerebellum

\begin{tabular}{|c|c|c|c|}
\hline Anterior lobe & $\left.\begin{array}{l}\text { I } \\
\text { II } \\
\text { III } \\
\text { IV } \\
\text { V }\end{array}\right\}$ & $\begin{array}{l}\text { Vermis } \\
\text { Lingula } \\
\text { Central lobule } \\
\text { Culmen }\end{array}$ & $\left.\begin{array}{l}\text { I } \\
\text { II } \\
\text { III } \\
\text { IV } \\
\text { V }\end{array}\right\} \begin{array}{l}\text { Ala centralis } \\
\text { Anterior semilunar } \\
\text { lobule }\end{array}$ \\
\hline \multicolumn{4}{|c|}{ 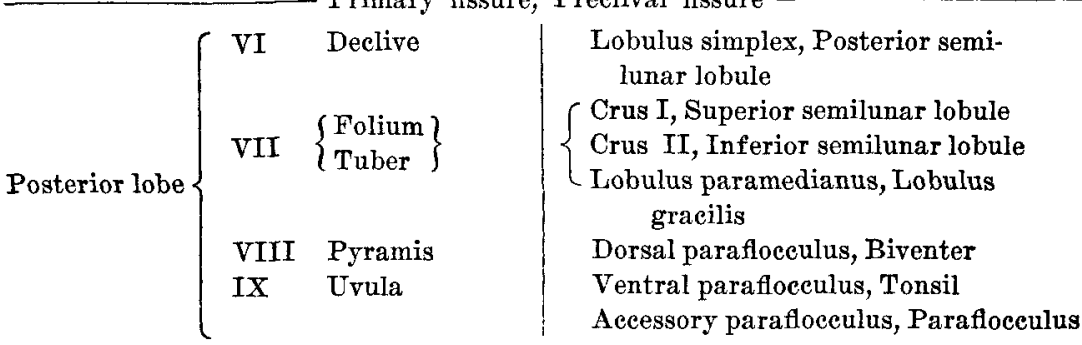 } \\
\hline $\begin{array}{l}\text { Floceulonodula } \\
\text { lobe } \\
\text { Nodule }\end{array}$ & & & Floceulus, Floceulus \\
\hline
\end{tabular}

The terminology of comparative anatomy is used and followed by the terminology of human anatomy. (Adapted from The Aspects of Cerebellar Anatomy, ed. by Jansen and Brodal, 1954, p. 75.) 
the parts of the cerebellum on the microscopic sections. The terminology (table 1; figs. 1,2 and 3) is based on that of Larsell ('51) and Jansen and Brodal ('54).

\section{EXPERIMENTAL RESULTS}

\section{Monkey I}

An attempt was made to destroy the left posterior gray column of the upper cord in this normal male macaque of $2.0 \mathrm{~kg}$ weight. After the removal of the left half of the first, the second, the fourth, the fifth and the seventh cervical and the first thoracic vertebral arches and cutting the dura, the spinal cord was exposed at three intervals between the intact laminae. The exposed cord was cauterized along the left posterolateral sulcus by an electrical current passed through a slim needle held at $30^{\circ}$ to the midsagittal plane of the cord, with its tip about $2.0 \mathrm{~mm}$ deep to the surface.

During the first few days after the operation the monkey showed marked hypotonicity of both forelimb and hindlimb on the left side. These two extremities were dragged and he was unable to jump, run, walk or climb effectively. The tendon reflexes of the affected limbs were not demonstrable. Sensory impairments were evident on the left forelimb, especially in its distal part, but it was not possible to demonstrate the exact extent of this loss. By the third postoperative day the monkey showed a slightly increased left knee jerk. Pathological responses could not be obtained on stimulation of the plantar surface of either foot. The animal could move his left forelimb voluntarily but feebly; he was unable to move his left hindlimb. Moderate hypotonicity was present in the left extremities. During the rest of the postoperative course the experimental findings were essentially unchanged. The animal was sacrificed two weeks after the experimental procedure.

At necropsy, gross lesions along the left posterolateral sulcus involved the whole length of the segments $\mathrm{C}_{2}, \mathrm{C}_{3}, \mathrm{C}_{6}, \mathrm{C}_{7}, \mathrm{~T}_{1}$ and $\mathrm{T}_{2}$. The left posterior nerve rootlets emerging at these levels were also destroyed.

Microscopically, the lesion at $\mathrm{C}_{2}$ and $\mathrm{C}_{3}$ includes the left dorsolateral fasciculus, the tip of the left dorsal horn, the most dorsal part of the left lateral funiculus and the lateral portion of the left dorsal funiculus. There is less involvement of the same areas at the levels of $\mathrm{C}_{6}$ and $\mathrm{C}_{7} . \mathrm{A}$ more extensive lesion at the first two thoracic cord segments reveals an irregular area of destruction. The cephalic sections of the lowest involvement $\left(\mathrm{T}_{1}, \mathrm{~T}_{2}\right)$ show the destruction of the left dorso- 
lateral portion of the cord, the deeper part of the left dorsal funiculus and the base of the right posterior gray horn. At the transition from $T_{1}$ to $T_{2}$, the lesion extends from the left dorsolateral fasciculus toward the central canal and destroys the left dorsal horn and both ventral funiculi. Followed caudad in $\mathrm{T}_{2}$, it includes the dorsal part of the left lateral funiculus and the left fasciculus gracilis.

In following the degenerated fibers, the components of the dorsal funiculus of the cord are considered first. Below the lowest lesion a number of scattered fibers can be identified on the left side as the fasciculus interfascicularis. This fasciculus occupies an elongated area between the fasciculus gracilis and the fasciculus cuneatus. It contains less fibers as it is followed caudalward.

The degeneration in the left fasciculus gracilis caused by the lesion at $T_{1}$ occupies a wedge-shaped area in the medial part of the dorsal funiculus. In the upper cervical region, the base of this area corresponds to the interval between the dorsomedian and the dorso-intermediate sulcus ; its apex is at the midpoint of the dorsomedian septum. The fibers of this fasciculus end in the nucleus gracilis. The whole mass of fibers and nucleus shows alternating white and gray layers, which, beginning in a dorsomedian position near the septum, accumulate in a ventrolateral direction.

The destruction of both the lateral part of the left dorsal funiculus and the left dorsal spinal nerve roots at the levels of the lesions produced a left fasciculus cuneatus degeneration. This fasciculus shows a complete degeneration above the level of each lesion, except for a short interval at the level of $\mathrm{C}_{4}$ and $\mathrm{C}_{5}$. Caudally, this spared area lies between the degenerated portion of the fasciculus dorsomedially and the tip of the dorsal horn ventrally (fig. 4). Progressing cephalad, the undestroyed area tends to spread ventromedialward and forms a lamina which is parallel to the lateral extent of the affected component of the fasciculus (fig. 5). This area is then included in the higher lesion. Above $\mathrm{C}_{3}$ the fasciculus again shows a complete degeneration. It ends partly in the nucleus cuneatus and partly in the lateral cuneate nucleus. The more ventromedial or deeper fibers project to the former nucleus, the more dorsolateral or more superficial fibers end in the lateral cuneate nucleus (fig. 6). A number of collaterals from the dorsal funicular fibers are observed penetrating the anterior gray horn of the same side, especially at the cervical enlargement.

Degenerated fibers produced by the most caudal lesion are also found in the ventral funiculi. Most of them are descending in course. No degenerated fibers can be allocated with certainty to the ventral spinocerebellar tract. A few scattered fibers found in the lateral funiculus on the side opposite the lesion belong to the lateral spino- 
thalamic tract. These scattered fibers can be traced as high as the most cephalic section of the series, which passes through the superior colliculi.

At $\mathrm{T}_{1}$ the left lateral funiculus reveals an extensive degeneration of its dorsal half. The descending degeneration represents the left lateral corticospinal and its accompanying tracts. The ascending path corresponds to the left dorsal spinocerebellar tract, which was almost completely destroyed at this level. It is related to the dorsal periphery of the lateral funiculus as usual. Progressing forward to the upper cervical cord, the tract, particularly in this case, gradually occupies a slightly deeper position in the substance of the lateral corticospinal tract (fig. 7). It then regains the usual superficial position at the caudal level of the motor decussation. Progressing cephalad, the area occupied by the dorsal spinocerebellar tract is gradually diminished in its vertical dimension and, at the same time, increases in its transverse extent. The dorsomedial shift of the more ventrally placed fibers makes these changes possible and these fibers occupy the medial portion of the tract. The degenerated fibers are more concentrated in the lateral part of the area. On entering the inferior cerebellar peduncle the dorsolateral fascicles are the first to swing dorsally and then occupy the ventral superficial part of the peduncle; the more ventromedially placed fascicles shift accordingly at the more cephalic level and gain a more dorsal, superficial location in the peduncle (figs. 8 and 9 ). Some fibers are seen to pass through the spinal tract of N.V.

Although there are some degenerated fascicles in this material due to cortical injury of unknown cause, the degenerated fibers of the left dorsal spinocerebellar tract can be traced to lobules II, III, IV, V, VIII and IX. The relative distribution of the fibers to the various lobules is shown in table 2. The dorsal spinocerebellar tract has a bilateral termination. The amount of crossed and uncrossed termination is approximately one to two in favor of the uncrossed fibers. The crossing occurs in the central white matter of the cerebellum. All fibers of the dorsal spinocerebellar tract are confined to the vermis with the exception of a few scattered fascicles extending into the closely adjoining hemisphere of the anterior lobe. The contralateral distribution shows less lateral extent.

\section{Monkey II}

A combined suboceipital craniectomy and removal of the posterior arch of the atlas were performed on this animal which was a healthy, normal young male macaque weighing $5.3 \mathrm{~kg}$. Electrical stimulation 
of the exposed portions of the cerebellum (pyramis, dorsal part of the uvula and the medial part of the biventral lobule of the right side) revealed a rough somatotopical pattern of motor responses on the posterior cerebellar vermis and the corresponding folia of the hemisphere, with the face area located dorsally on the pyramis and the neck and the shoulder areas more ventrally. A lesion was produced by the usual electrical cauterizing current at the point which had given a shoulder response on stimulation.

One week later, the second operation was performed on this monkey which had behaved normally since the first operation. A cordotomy by a tangential cut was carried out in the left dorsolateral region at the level of $\mathrm{C}_{2}$.

There were no significant, abnormal elinical findings during the one-week course after the first operation. Following the second operation, the monkey showed moderate hypotonicity of both left extremities with weak grasp and diminished tendon reflexes especially in the left lower limb. Interference with placing was evident in the affected limbs. No paralyses or pathological reflexes were present. The monkey did not show any detectable change in clinical findings during the three weeks after the second operation, except for the return of the normal tendon reflexes at the end of the first week. He was sacrificed by the usual method three weeks after the second operation.

Two lesions were recognized on the gross material at necropsy. The first one, a spherical area of $1.5 \mathrm{~mm}$ diameter, was located superficially in the hollow between the ventral part of the right side of the pyramis and the adjoining hemisphere (fig. 2). The second lesion, a clean, cross streak, was present at the left dorsolateral aspect of the cord at $\mathrm{C}_{2}$.

Microscopically, the degenerated fibers produced by the cortical lesion project centrally to the region around the nucleus fastigii and the medial aspect of the nucleus interpositus of the same side. Some of the degenerated fibers are also found in the region of the opposite nucleus fastigii. It is noteworthy that a great number of degenerated fibers is present in the caudal levels of the nuclei, with a few fibers reaching the cephalic levels.

Ascending degenerations, following the cord lesion, are present in both the left dorsal and the left lateral funiculi because of the tangential cut in the left dorsolateral quadrant of the cord. A partial destruction in the dorsal part of the left fasciculus gracilis was observed and the degeneration followed forward to end in the dorsal part of the left nuclens gracilis. Only approximately the superficial half of the left fasciculus cuneatus is included in the lesion. The degenerated fibers progress cephalad to terminate in the left lateral cuneate nucleus 
at all levels; some of the deeper portion of the degenerated component of the fasciculus end in the left nucleus cuneatus (fig. 11).

At the highest cervical level, a thick layer of degenerated fibers is present along the periphery of the left lateral funiculus. These fibers occupy an area extending between the ventral limit of the spinal tract of N.V and its nucleus dorsally and a point approximately equidistant between the left posterolateral sulcus and the anteromedian fissure ventrally. The degenerated fibers are more closely arranged at the periphery of the area, with a few fibers scattered in the deeper portion. These scattered fibers shift dorsolaterally as they ascend and they become definitely incorporated into the loose middle portion of the main bundle in the lower medulla. Mostly, the degenerated fibers in the lateral funiculus belong to the dorsal spinocerebellar tract dorsally and the ventral spinocerebellar tract ventrally; but it is impossible to establish a definite boundary between these two tracts at this level.

At the caudal level of the inferior olivary nucleus, the degenerated dorsal spinocerebellar fibers are concentrated in the dorsal part of the degenerated area and the degenerated ventral spinocerebellar fibers in the ventral part, with a loosely packed bundle lying between the two main groups (fig. 11). At higher levels, the dorsal part of the last mentioned bundle joins the dorsal spinocerebellar tract as its most ventromedial component; the ventral part of the bundle joins the ventral tract as its dorsal component.

The degenerated dorsal spinocerebellar fibers progress forward and shift dorsad to enter the inferior cerebellar peduncle. The relations and the orders of shifting in the bundle (fig. 10) are essentially similar to those described for Monkey I. The degenerated fibers of the dorsal spinocerebellar track occupy the superficial part of the peduncle, with less fibers in its dorsal superficial portion. The degenerated fibers tend to spread out and shift medially in the higher levels of the peduncle. In the central white matter of the cerebellum, they curve dorsally around the cephalic tip of the dentate nucleus. The dorsal spinocerebellar fibers then lie lateral and dorsal to the beginning of the brachium conjunctivum.

In the high medulla, the degenerated ventral spinocerebellar fibers occupy an area along the surface of the medulla between the spinal tract of N.V dorsally and the inferior olive ventrally. The largest number of degenerated fibers are concentrated in the ventral part of the area; a few scattered fibers are present in the dorsal part (fig. 10). The degenerated fibers continue forward and turn dorsalward, beginning just cephalic to the intramedullary course of the trigeminal fibers. They curve around the lateral side of the brachium conjunctivum and 
then ascend caudodorsalward along its superomedial aspect to enter the cerebellum. The more dorsolateral fibers in the medulla seem to be the first to turn and lie, finally, in a more lateral part of the area occupied by the tract in the superior cerebellar peduncle. The decussation of the trochlear nerves indicates the highest level of the brainstem at which the ventral spinocerebellar fibers can be found.

The relative distribution of the degenerated spinocerebellar fibers to the various subdivisions of the cerebellum is presented in table 2 . The determination is less accurate because of the fragmented condition of the material in this series and the degenerated fibers from the cerebellar lesion make it impossible to determine the extent of the spinocerebellar distribution in lobule VIII. The spinocerebellar tracts end bilaterally but predominantly on the side of the lesion. The crossing is approximately in 1:2 proportion. The same lateral limits of distribution, mentioned for the previous monkey, are confirmed.

\section{Monkey III}

Two operations were performed on this healthy, normal young female macaque of $2.2 \mathrm{~kg}$ weight. The first operation, a right lateral cordotomy at about the level of $\mathrm{S}_{1}$, was done by a transverse cut beginning at the right posterolateral sulcus. Two weeks later another cordotomy was carried out at $\mathrm{C}_{8}$ by two tangential cuts in order to destroy the periphery of the left lateral funiculus.

During the two-week period after the first operation, the animal showed only a slight weakness at the right ankle with a loose grasp. After the second operation, the left hind limb was markedly hypotonic with a negative knee jerk and negative placing and grasping reactions. No paralysis or Babinski's reflex was evident. The left forelimb showed only a slight weakness of muscular tonus with a loose grasp. A positive placing reaction was obtained in this limb. The right hindlimb still revealed the same clinical findings as before. No abnormal movements or postures could be observed other than an ineffective Iocomotion due to the hypotonic limbs. By the end of the first week after the second operation, a slight left knee jerk returned and the right foot appeared normal. From now on until the time of sacrifice, which was the fourteenth day after the second operation, no significant, detectable changes were recorded. A routine formalin perfusion was done under ether anesthesia and the brain and the whole spinal cord with its attached nerve roots were removed for microscopic preparations.

Only the more rostral microscopic sections beginning with the upper cervical level are serviceable. At all levels a small number of degener- 
ated fibers of the right ventral spinocerebellar tract, produced by the lesion at $S_{1}$, are loosely arranged in an area corresponding with the compact, dorsolateral portion of the left ventral spinocerebellar tract (fig. 13).

At upper cervical levels, a heavy collection of Marchi granules in the periphery of the left lateral funiculus, represents the ascending degeneration of the left dorsal and the left ventral spinocerebellar tracts produced by the left lateral cordotomy at $\mathrm{C}_{8}$. The degenerated fibers of the left dorsal spinocerebellar tract occupy the dorsal half of the periphery of the left lateral funiculus, leaving only a thin layer of corticospinal fibers superficial to the spinocerebellar fibers. The tract regains a superficial position when the caudal level of the motor decussation is reached. The degenerated fibers of the left ventral spinocerebellar tract are located in the ventral half of the periphery of the left lateral funiculus, with more fibers concentrated in its dorsolateral portion. A point approximately equidistant between the dorsal and the ventral spinal nerve roots seems to be the junction of the two spinocerebellar tracts at this level. Essentially, the microscopic descriptions of both left spinocerebellar tracts correspond with those for Monkey II, as regard to the courses and the arrangement of their component parts. The final distribution of the degenerated spinocerebellar fibers in the cerebellum is shown in table 2 .

It is worthwhile to mention that an adventitious degeneration is present as a definite oblique band in the most dorsomedial area of the left fasciculus cuneatus. These degenerated fibers ascend and terminate in the corresponding dorsomedial portions of the lateral cuneate nucleus and the nucleus cuneatus.

\section{Monkey IV}

This healthy normal young female macaque weighing $2.0 \mathrm{~kg}$ was the subject of a right cordotomy at the level of $\mathrm{T}_{10}$. The tangential cut included the posterior funiculi and the right lateral funiculus at this level.

Postoperatively, the animal showed marked hypotonicity and weakness of the right hind limb. No grasping and placing reactions could be obtained from this limb and no paralyses or pathological reflexes were present in it. A slightly positive right knee jerk was detected. During two weeks after the operation, there were no significant changes except for the return of the normal right knee jerk and a slight recovery of the muscular tonus of the right hind limb, more especially in its proximal portion. These changes were found one week after the operation. 
The animal was perfused under an ether anesthesia on the fourteenth day after the operation. The brain and the whole spinal cord were removed. The cerebellum, the brainstem and the upper cervical cord are available in the Marchi series.

At upper cervical levels, the degenerations, as studied in Marchi preparations, occur in the fasciculi graciles and the right dorsal and the right ventral spinocerebellar tracts. There are some adventitious degenerations in the left lateral funiculus especially in the area occupied by the dorsal spinocerebellar system. The microscopic descriptions of the degenerated fasciculi graciles will be omitted here because they correspond essentially with those for Monkey I. The degenerated fibers of the right dorsal and the right ventral spinocerebellar tracts, produced by the complete destruction of the tracts at $\mathrm{T}_{10}$, are concentrated in the elongated dorsolateral areas of their corresponding tracts. There are only a few degenerated fibers scattered ventromedial to these main areas of degeneration (figs. 12a, b and $\mathrm{c}$ ). The dorsal limit of the right ventral spinocerebellar tract is approximately at a point halfway between the right posterolateral sulcus and the right ventrolateral sulcus of the cord. As the right ventral spinocerebellar tract is followed towards the medulla, the position of its degenerated component is gradually changed so that, at cephalic levels of the inferior olivary nucleus, the degenerated fibers are located mainly in the ventral area of the tract (fig. 12d). The degenerated ventral spinocerebellar tract again shows, in its course to the cerebelIum, the same general pattern as that described for it in Monkey II.

The degenerated fibers of the right dorsal spinocerebellar tract continue forward, gradually increased in their transverse extent by the dorsomedial shift of the more ventrally placed fibers. At caudal levels of the medulla, the degenerated fibers are located ventral to the nucleus of the spinal tract of N.V, with more concentration laterally (fig. 12b). As the dorsal spinocerebellar fibers enter the inferior cerebellar peduncle, a dorsal shift of the fibers occurs in the same general pattern as was described for Monkey I. The degenerated fibers are located chiefly in the ventral superficial part of the peduncle. The relative distribution of the degenerated spinocerebellar fibers within the cerebellum in this animal is shown in table 2.

\section{Monkey $V$}

This normal young and healthy male macaque of $5.5 \mathrm{~kg}$ weight was operated upon twice at a one-week interval. At the first operation a left ventral spinocerebellar tractotomy was done at $\mathrm{C}_{2}$ and a direct cut was also made in the left clava. The second operation was 
performed on the left cerebral hemisphere (area 9 and the lower part of the sensory cortex) by another investigator who will report his own results.

After the first operation, the animal showed only slight weakness and hypotonicity of the left hind limb, with no detectable defects on the left forelimb. The tendon reflexes remained normal as well as the placing and the grasping reactions. No paralyses or pathological reflexes were evident. On subsequent postoperative examinations over the next three weeks the clinical observations revealed no significant changes even after the second operation. The animal was sacrificed two weeks after the second operation with the usual formalin perfusion under a large dose of evipal injected intraperitoneally.

Microscopically, a complete destruction of the left ventral spinocerebellar tract and a slight degeneration in the dorsal spinocerebellar tract were evident at $\mathrm{C}_{2}$. The degenerated ventral spinocerebellar fibers occupy the ventral periphery of the left lateral funiculus. Medially, there is a number of scattered fibers which, presumably, are fibers of the lateral spinothalamic tract and the spinotectal tract (fig. 14b). The degenerated fasciculi, when traced cephalad into the medulla, occupy an area dorsolateral to the inferior olive (fig. 14a). The ventral spinocerebellar tract contains the larger myelinated fibers. These fibers are compactly arranged along the surface of the medulla extending between the spinal tract of N.V dorsolaterally and the inferior olive ventromedially. The finer fibers of the lateral spinothalamic and the spinotectal tracts are dispersed medially to the ventral spinocerebellar tract and immediately above the inferior olive. Approaching the cerebellum, the ventral spinocerebellar tract reveals the same course and relations described for it in Monkey II. In this monkey the destination of the ventral spinocerebellar tract within the various cerebellar subdivisions, which is shown in table 2, has been determined in sagittal sections of the vermis.

An undercut along the long axis of the left clava caused a degeneration of the left internal arcuate fibers as they passed from the ventral aspect of the left nucleus gracilis. These fibers make a series of great loops across the field of the medulla and totally cross the midline to constitute the gracile component of the right medial lemniscus, which reveals normal relations in its course forward. No degenerated my. elinated fibers can be followed from the nucleus gracilis into the inferior cerebellar peduncle.

\section{Monkey VI}

This young male macaque weighing $5.2 \mathrm{~kg}$ had had left cortical areas 8 and 11 destroyed by another investigator 9 days before the 
present experiment. The animal revealed no neurological deficits when examined before our own operation, which was a left dorsal spinocerebellar tractotomy at $\mathrm{C}_{2}$.

Postoperatively, the monkey showed the same clinical picture as did Monkey $\mathrm{V}$. He was sacrificed on the fourteenth day after our own operation, with the routine formalin perfusion under an intraperitoneal evipal injection.

Microscopically, as studied in Marchi preparations, the left dorsal spinocerebellar tract shows a complete degeneration at upper cervical levels. The degenerated fibers occupy an area close to the periphery of the dorsal part of the left lateral funiculus. They are grouped in fasciculi, scattered among the superficial bundles of the left lateral corticospinal tract. The left dorsal spinocerebellar tract extends across the left lateral funiculus, between the posterior gray horn dorsomedially and a point approximately halfway between the dorsal and ventral spinal nerve roots ventrolaterally. The dorsomedial portion of the tract occupies a wider area and lies close to the surface of the cord. Ventrolaterally, the tract is more tapering and lies deeper in the substance of the lateral corticospinal tract (fig. 15c).

At the level of the motor decussation, the dorsal spinocerebellar tract regains a superficial position. With a gradual, dorsomedial shift of the more ventrally placed fibers, the transverse extent of the dorsal spinocerebellar tract increases and its vertical dimension correspondingly diminishes (fig. 15b). The degenerated fibers are more compactly arranged in the lateral portion of the area, which is located in the angle between the surface of the medulla and the nucleus of the spinal tract of N.V.

Progressing cephalad, the degenerated left dorsal spinocerebellar tract reveals the usual dorsal shift to enter the inferior cerebellar peduncle. The degenerated fibers occupy, mainly, the ventral superficial part of the peduncle (fig. 15a). The relative distribution of the dorsal spinocerebellar tract within the cerebellum, as determined in sagittal sections of the vermis, is given in table 2 .

A diffuse degeneration occurs in the left ventral spinocerebellar tract but it does not contribute any additional significant information. A few degenerated fibers in the lateral part of the left fasciculus cuneatus have confirmed the pattern of termination of this fasciculus.

\section{Monkey VII}

A right ventrolateral cordotomy by a direct cut at about $\mathrm{L}_{2}$ was performed on this young normal male macaque weighing $3.0 \mathrm{~kg}$.

After the operation, the monkey had a paralysis of the right hind limb. This limb was flaccid and could not be used in locomotion. It 
was not possible to obtain either the Babinski's reflex or the grasping or placing reactions of the right hind limb. Otherwise no abnoral clinical findings were evident. The animal was kept alive for a threeweek postoperative period, during which time there were no significant changes in clinical findings. He was sacrificed on the twenty-first day after the operation, with the usual formalin perfusion under an intraperitoneal evipal injection. The brain and the whole spinal cord were removed for microscopic preparation but only the cerebellum, the brainstem and a number of selected levels of the cord (lower lumbar, upper lumbar, middle thoracic and lower and upper cervical segments) are available in Marchi stain.

Microscopic examination at lower lumbar levels reveals a degeneration at the periphery of the right ventral and the right lateral funiculi which also includes the right lateral corticospinal tract. Diffuse degenerations are found all over the rest of the cord at this level.

At upper lumbar levels, the degenerated fibers of the spinocerebellar system are concentrated in the periphery of the right lateral funiculus. The dorsal spinocerebellar tract forms a narrow strip along the surface of the cord. It extends from the posterolateral sulcus dorsomedially to a point approximately halfway between the dorsal and the ventral nerve roots ventrolaterally. The ventral spinocerebellar tract occupies the ventrolateral periphery of the cord, with a densely packed comet-shaped area in its most dorsolateral part. A broader ventromedial portion contains diffuse, degenerated fibers, which, presumably, belong partly to the lateral spinothalamic tract. The dorsal extent of the ventral spinocerebellar tract is approximately $1 \mathrm{~mm}$ below the most ventral limit of the degenerated right dorsal spinocerebellar system (fig. 16).

At middle thoracic levels, the ventral spinocerebellar tract remains relatively unchanged in its position and in its fiber arrangement. The degenerated dorsal spinocerebellar tract still occupies the dorsal half of the periphery of the lateral funiculus, with a slender extension projecting ventromedially from the most dorsal portion of the area. This projection lies between the dorsolateral fasciculus dorsomedially and the lateral corticospinal tract ventrolaterally (fig. 16).

At lower cervical levels, the area occupied by the dorsal spinocerebellar tract becomes broader dorsomedially and more tapering ventrolaterally, because of the dorsomedial shift of degenerated fibers. With this shift of the dorsal spinocerebellar fibers, a larger interval between the dorsal and the ventral spinocerebellar tracts is evident. The position and the general outline of the ventral spinocerebellar tract remain the same, with an increase in the number of degenerated fibers in its densely packed, dorsolateral portion (fig. 16). 
Upper cervical cord levels reveal scattered bundles of the dorsal spinocerebellar tract in the substance of the lateral corticospinal system similar to those deseribed for Monkeys I, III and VI. The dorsomedial shift of the more ventrally placed dorsal spinocerebellar fibers continues so that, at the level of the motor decussation, the area occupied by this tract is much diminished in its vertical dimension, with an increase in its transverse extent. The major portion of the degenerated fibers is concentrated laterally in an area which is located in the angle between the surface of the medulla and the nucleus of the spinal tract of N.V. Continuing forward, the dorsal spinocerebellar fibers show the usual pattern of shifting as they enter the inferior cerebellar peduncle and, for the most part, occupy its ventral superficial portion (fig. 17).

The ventral spinocerebellar tract progresses cephalad in the same position in the cord, with more fibers incorporated in the ventromedial aspect of its densely arranged, dorsolateral portion. As followed forward to the medulla, the ventral spinocerebellar tract occupies a superficial area dorsolateral to the lateral portion of the inferior olive. At mid inferior olivary levels, most of the degenerated fibers are located in the ventral portion of the area (fig. 17). Approaching the cerebellum, both the dorsal and the ventral spinocerebellar tracts follow essentially the same courses and have the same pattern arrangments of their fibers as was demonstrated for them in material prepared from the earlier operated animals.

As determined in sagittal sections of the vermis, the relative distribution of the degenerated spinocerebellar fibers within the cerebellar subdivisions is represented in table 2. In order to reach the posterior vermis, the fibers run caudalward, mainly, above the cerebellar nuclei.

It is noteworthy that there are diffuse degenerations in the spinocerebellar tracts of the side opposite the lesion. The general outlines of these areas of degeneration correspond roughly with the degenerated portion of the equivalent tracts on the side of the lesion.

\section{Monkey VIII}

This animal was a healthy, normal young male macaque of $2.5 \mathrm{~kg}$ weight. The medulla and the inferior aspect of the cerebellum were exposed in the operation. A small uninsulated needle was inserted $2 \mathrm{~mm}$ into the lateral part of the left cuneate tubercle. In order to destroy the left lateral cuneate nucleus, a 3 ma of cauterizing eurrent was passed through the electrode for 60 seconds before it was removed.

Postoperatively, the monkey showed a slight weakness and hypotonicity of the left extremities. The tendon reflexes remained equal 
and normal except for the slightly diminished left knee jerk. No abnormal reflexes or paralyses were present. Placing tests revealed normal reactions for all extremities. No abnormalities were found in the facial movements or in the position of the head and neck. By the end of the first week after the operation, the animal was observed to keep his face turned toward the side of the lesion. The tonus of the affected extremities seemed to regain normal quality at this time. The monkey showed normal knee jerks and improvement in using his extremities. He still had a slight weakness of grasp in his left forelimb. No significant changes were noted from this time until the time of sacrifice which was the fourteenth postoperative day.

As studied in Marchi preparations, the lesion extends forward from the caudal part of the left lateral cuneate tubercle to the left reticular formation of the pontine region. The lesion involves the dorsal portion of the inferior cerebellar peduncle as it lies superficial to the cuneate tubercle, the deeper part of the whole length of the lateral cuneate nucleus and the cephalic portions of the nucleus gracilis and nucleus cuneatus. Farther rostrad, the lesion affects a comparatively small segment of the nueleus of the spinal tract of N.V and the lateral part of the reticular formation of the medulla and the pons. The uvular cortex, also, has been injured by a spread of the current used in making this lesion.

A large number of degenerated fibers enters the deep aspect of the left inferior cerebellar peduncle and is then concentrated in its dorsal superficial portion (fig. 19). The major components of these fibers are from the partly destroyed lateral cuneate nucleus and dorsal spinocerebellar tract. A much smaller number of degenerated fibers of the peduncle consists of olivocerebellar fascicles, fibers from the lateral reticular nucleus and, possibly, fibers from the nucleus of the spinal tract of $N$. V. The relative distribution of the degenerated fibers of the inferior cerebellar peduncle within the cerebellum is given in table 2. The degenerated fibers to the inferior vermis could be determined with less accuracy because of the presence of adventitious fibers from the accidental cortical degeneration. The material prepared from this monkey shows within the cerebellum, limits of distribution of the tracts laterally and that the crossing of their fibers is in a 1:2 proportion, as was described for Monkey I.

Streams of degenerated fibers leave the ventral aspect of the left nucleus gracilis and the left nucleus cuneatus and form a series of wide loops across the field. They cross the midline to enter the right medial lemniscus. The lemniscus continues its usual course forward. 


\section{Monkey IX}

This male macaque weighing $2.5 \mathrm{~kg}$ was a young, healthy and neurologically normal monkey. A transtentorial approach was used on this monkey in order to explore the left superior surface of the cerebellum. The exposed portions of the cerebellum included the declive (lobule VI), the culmen (lobule V) and the adjoining left hemisphere. The usual method of electrical stimulation with the routine setting of the same apparatus as that employed previously was used in stimulating the surface cortex of the exposed cerebellum. The results suggested a pattern of responses in relation to the body topography, with the declive and its corresponding hemisphere showing the neck responses. More anteriorly, the posterior part of the anterior lobe revealed a combination of neck and shoulder girdle movements when it was stimulated. These responses occurred on the side of the stimulation. A cortical lesion was produced by electrical cauterization and enlarged with cotton swab in the region of the left primary fissure (preclival fissure) close to the midline (fig. 1). Except for a right homonymous hemianopsia due to the excision of the left occipital pole of the cerebrum, the animal showed no detectable, clinical ab. normalities.

Two weeks after the operation just mentioned, the animal was again operated under ether anesthesia. The inferior surface of his cerebellum was exposed and stimulated.

An electrical current of the usual frequency and strength was employed to stimulate the exposed cerebellar cortex of the pyramis, the dorsal part of the uvula and the medial half of the right cerebellar hemisphere. The following results were obtained on the side of stimulation: Neck movements were seen when stimulating the lobulus paramedianus (L. gracilis), the dorsal part of the pyramis and its lateral extension into the hemisphere. The ventral part of the pyramis and the middle folia of the dorsal parafloceulus (biventral lobule) revealed shoulder responses; more ventrally, stimulation of the dorsal part of the uvula and the caudal folia of the dorsal paraflocculus yielded slight contractions of the muscle of the upper arm. The animal was sacrificed just after the procedure with a formalin perfusion.

The cortical lesion of $5 \times 8 \mathrm{~mm}$ size (as examined at necropsy) involves the declive (lobule VI), the posterior lobule (lobule V) of the culmen and their continuations into the adjoining medial portion of the left hemisphere (fig. 1). Microscopic examination of Marchi preparations shows the major bundles of the degenerated fibers from the lesion reaching the dorsal aspect of the middle and the anterior portions of the nucleus fastigii and the nucleus interpositus on the same 
side. At more caudal levels of the nuclei, a small number of Marchi granules is present at the transition of the nucleus interpositus into the nucleus dentatus. A number of fibers also has been traced to the medial side of the contralateral nucleus fastigii. The degenerated fibers appear to project onto the cerebellar nuclei with the more medially placed fibers reaching the more medial nuclear mass and the more lateral fibers ending in the more lateral portion of the nuclear mass. No degenerated fibers could be traced either to the other parts of the cortex or the brainstem.

\section{Monkey $X$}

A young, healthy appearing male macaque of $3.0 \mathrm{~kg}$ weight, with a normal neurological status was the subject of a right suboccipital eraniectomy. The purpose of this operation was to explore the inferior surface of the right cerebellar hemisphere. The usual setting of the electrical stimulator was employed in stimulating the cerebellar cortex. The head and neck movements were obtained when stimulating the folia on either side of the prepyramidal sulcus. When the electrode was moved eaudalward on the dorsal parafloceulus (biventral lobule), a retraction of the shoulder was noted accompanying the neck movement. All responses occurred homolaterally. A lesion was produced on the cerebellar cortex over the prepyramidal fissure (fig. 2). A cotton swab was employed in enlarging the lesion. The destroyed cortex represented the area which had revealed, mainly, the head and neck responses on stimulation.

During the three-week postoperative course, the animal did not show any detectable abnormalities. At the end of the period, he was sacrificed with a formalin perfusion under ether anesthesia. The lesion ( $5 \times 7 \mathrm{~mm}$ size, as examined macroseopically at postmortem) was situated over the prepyramidal fissure and its center was $8 \mathrm{~mm}$ to the right of the midline (fig. 2). The lesion involved the lobulus paramedianus (L. gracilis) and the cephalic folia of the dorsal paraflocculus (biventral lobule).

Microseopie study of Marchi preparations made from the material revealed that the degenerated fibers project homolaterally from the lesion towards the caudal levels of the three cerebellar nuclei. Slightly more cephalad, major bundles of fibers reach the dorsomedial aspect of the nucleus interpositus and the lateral side of the nucleus dentatus. Marchi granules are also found in the tuber (and folium vermis), the pyramis and the uvula on both sides with greater distribution on the side of the lesion. A number of degenerated fibers is present in Crus I 
(superior semilunar lobule) and the caudal folia of the dorsal paraflocculus (biventral lobule).

\section{Monkey XI}

Two operations were performed on this normal young male macaque weighing $2.7 \mathrm{~kg}$. The first operation was an exposure of the left superior surface of the cerebellum by using a transtentorial approach. The exposed region, including the medial part of the posterior semilunar lobule and the posterior part of the anterior semilunar lobule, was stimulated electrically with the routine setting of the Grass stimulator, while the animal was still under ether anesthesia. The homolateral neck muscle responses were obtained when stimulating the posterior semilunar lobule. The posterior folia of the anterior semilunar lobule showed, on stimulation, some ipsilateral shoulder girdle movement in addition to the neck responses. A cortical lesion was produced by electrical fulguration in the middle portion of the superior surface of the left posterior semilunar lobule. Finally, the lesion was enlarged by employing cotton pledgets.

The monkey was apparently normal for 7 days after this operation. No abnormal clinical findings were detectable, except for the impairment of the right visual field. One week after the first operation, he was the subject of another operation performed on the right inferior surface of the cerebellum. Under ether anesthesia, the exposed portion of the cerebellum - including the pyramis, the uvula and the dorsal paraflocculus (biventral lobule) of the right side - was stimulated electrically. The routine setting of the stimulator was employed. The results revealed that the neck movement was represented in the dorsal part of the pyramis and the cephalic folium of the dorsal paraflocculus. More caudally, neck and shoulder movements were obtained. The dorsal part of the uvula and the caudal folia of the dorsal parafloceulus showed responses of the upper $\operatorname{limb}$ with the shoulder area located more cephalad. The responses were observable on both sides only when the stimulation was carried on near the midline. Otherwise the results were obtained entirely on the side of the stimulation. Then a cortical lesion was put in the middle of the right dorsal paraflocculus by electrical fulguration and enlarged with cotton swabs.

After the second operation, the monkey showed no abnormalities other than a defect of the right visual field, which had persisted since the first operation. The animal was then sacrificed under ether anesthesia, two weeks after the second operation by the usual formalin perfusion. His brain and upper cervical cord were removed. Grossly, one lesion was present on either surface of the cerebellum (figs. 1 and 
2). A $5 \times 7 \mathrm{~mm}$ lesion on the left superior surface was located in the middle region of the posterior semilunar lobule and extended somewhat into the posterior part of the anterior semilunar lobule. The center of the lesion was $12 \mathrm{~mm}$ to the left of the midline. On the inferior surface of the cerebellum, a lesion of $5 \times 7 \mathrm{~mm}$ size involved the right half of the dorsal portion of the uvula, the caudal folia of the dorsal paraflocculus and the middle part of the cephalic folia of the same lobule.

In Marchi preparations, the degenerated fibers from the lesion on the superior surface of the left cerebellar hemisphere, can be traced lateralward to the lateral portion of the same hemisphere; they are present in the anterior, posterior, superior and inferior semilunar lobules, with definitely more fibers reaching the superior semilunar lobule. The degenerated fibers also extend medially into the culmen (lobule IV and V), the declive (lobule VI) and the tuber-folium vermis (lobule VII) on both sides, with many more fibers distributing on the side of the lesion. The fibers which cross the midline are concentrated medially and the crossing occurs in the vermis itself. The degenerated fibers have been traced centrally to terminate in all homolateral cerebellar nuclei, with a comparatively few fibers reaching the dorsal aspect of the nucleus fastigii. The nucleus dentatus, except for its ventromedial part, receives, at all levels, a large contribution from the cortical lesion. Many degenerated fibers terminate in the dorsal and the lateral portion of the nucleus interpositus at all levels except for its cephalic end. The lateral part of this nucleus and its transition into the nucleus dentatus receives the greatest number of fibers.

From the cortical lesion on the right hemisphere, the degenerated fibers have been followed centrally to end in all nuclear masses on the same side and in the nucleus fastigii on the opposite side. A large number of degenerated fibers reaches the ventromedial aspect of the nuclei fastigii at caudal levels, with approximately the same extent of distribution on both sides. On the side of the lesion, at caudal levels, the nucleus interpositus, including its transitions into the other two nuclei, receives a number of fibers on its medial and lateral aspects. At more cephalic levels, the dorsal part of this nucleus is also the site of termination of degenerated fibers. No contributions have been seen at the cephalic pole of the nucleus interpositus. Approximately the cephalic half of the ventrolateral part of the nucleus dentatus receives a number of fibers which are more laterally placed. Degenerated association fibers have been found within the pyramis, the uvula, the dorsal paraflocculus and the lobulus paramedianus. A considerable amount of crossed fibers is also present within the vermis. In this case, the degenerated fibers again seem to project onto the cerebellar 
nuclei, principally, with the more medial fibers to the medial nuclear mass and the more intermediate to intermediate portion. Projections from the cerebellar cortex to the other parts of the central nervous system, if any, have not been recognized.

SYNTHESIS OF OBSERVATIONS

\section{The dorsal spinocerebellar tract}

Material from 6 experimental animals (Monkeys I, II, III, IV, VI and VII), prepared by the Marchi technique, was used in determining the course, the fiber arrangement and the termination of the dorsal spinocerebellar tract. Experimental lesions of the tract at the levels of $\mathrm{L}_{2}, \mathrm{~T}_{10}, \mathrm{~T}_{1}, \mathrm{C}_{8}$, or $\mathrm{C}_{2}$ were carried out with a duplication of the experiment at $\mathrm{C}_{2}$. A complete, or almost complete, degeneration of the dorsal spinocerebellar tract at the level of the lesion is believed to have been obtained from each experiment. In almost all cases, the ventral spinocerebellar tract on the side of the lesion was more or less involved.

A large number of the dorsal spinocerebellar fibers arises from below $\mathrm{L}_{2}$, as was found in Monkey VII with a cord lesion at this level. At $\mathrm{L}_{2}$ these degenerated fibers are already organized into a narrow area along the surface of the cord, extending from the dorsolateral sulcus to a point approximately at the transverse level of the central canal. The broader ventral end of the area occupied by this tract is separated from the ventral spinocerebellar tract by a narrow interval. Progressing cephalad, a gradual, dorsomedial shift of the dorsal spinocerebellar fibers is evident. The shift continues, so that, at the lower cervical cord, the degenerated fibers are concentrated in an area ventrolateral to the dorsolateral fasciculus, with a broader dorsomedial part and a tapering ventrolateral end. The interval between the two spinocerebellar tracts persists and becomes more evident with the retraction of the ventrolateral limit of the degenerated dorsal spinocerebellar tract towards its main mass.

At upper cervical levels, a special relation between the dorsal spinocerebellar tract and the lateral corticospinal tract 
should be emphasized. The dorsal spinocerebellar tract breaks into scattered bundles which intermingle to some extent with the fascicles of the lateral corticospinal tract, as is found in Monkeys I, III, IV, V and VII. The more ventrally placed fascicles lie more deeply in the cord and the whole tract occupies more space in a dorsomedial-ventrolateral direction than it has in the lower cervical cord. Unfortunately, in addition to the existence of these features, the sections of the spinal cord lower than the upper cervical segments, obtained from the monkeys with lesions at $\mathrm{T}_{10}$ and $\mathrm{C}_{8}$, are not serviceable, so the position of these fibers at upper cord levels cannot be documented.

The dorsal spinocerebellar fibers are reorganized, at the levels of the motor decussation, in an area between the surface of the medulla laterally and the nucleus of the spinal tract of N.V dorsomedially, with more concentration of fibers in the more lateral part of the area. The fibers in the loosely packed, medial part consist of the more ventrally placed fibers of the tract seen in the lower levels. This condition can be clearly observed, at the uppermost cervical cord, in Monkey II, III and VI with lesions at $\mathrm{C}_{2}, \mathrm{C}_{8}$ and $\mathrm{C}_{2}$ respectively. In these cases, the degenerated dorsal spinocerebellar tract occupies more area ventrally along the surface of the cord down to the dorsal limit of the ventral spinocerebellar tract. In other words, at least in upper cervical levels, the interval, which has persisted between the degenerated dorsal and ventral spinocerebellar tracts at lower levels, is occupied by additional degenerated fibers produced by the lesions in cervical cord. These cervical fibers, by a dorsomedial shift, acquire a position in the medial part of the dorsal spinocerebellar tract at the levels of the motor decussation. In the series of operated animals, the number of degenerated fibers in the dorsal spinocerebellar tract increased as the cord lesion became successively nearer the brain. Although the area occupied by the degenerated fibers in the medulla does not show great increase medially in the monkey with higher cord injuries, as compared with those with lesions at lower cord levels, nevertheless the fibers 
in the medial part of the tract are more densely arranged in the former group of animals. It may be concluded, then, that the fibers arising from the higher levels of the cord are added first to the ventral aspect of the tract, then shift dorsomedially to occupy a medial position at caudal medulla levels. Therefore, a topical arrangement of the dorsal spinocerebellar fibers does exist at these latter levels but with a considerable overlap of pattern.

In all cases, it is evident that the dorsal spinocerebellar fibers continue turning dorsomedially in order to enter the inferior cerebellar peduncle. At the beginning, they form a thin sheath overriding the dorsolateral surface of the cuneate tubercle. At the level where the peduncle has been well established, the dorsal spinocerebellar tract occupies the superficial portion of the peduncle, with a broader and more densely packed area ventrolaterally. The more laterally placed fibers in the tract in the medulla are located in the ventrolateral part of the tract in the peduncle; the more medial fascicles make a great turn in the dorsal direction and finally occupy the more dorsal superficial position in the peduncle. It is worthwhile mentioning that the innermost fascicles do not turn dorsally until more cephalic levels are reached. Then they make a sharp bend and ascend medial to the main degenerated mass to occupy the most dorsal superficial portion of the tract in the peduncle. The ventrolateral portion of the tract remains essentially unchanged in either its mediolateral extent or its fiber concentration in relation to the lesions at different levels obtained from these series. On the contrary, the additional degenerated fibers, obtained from the lesions at higher levels, can be traced to the more dorsomedial portion of the tract. It can be concluded, therefore, that the topical arrangement of the dorsal spinocerebellar tract can be recognized in the inferior peduncle before the distribution of the tract to the cerebellum. It is, of course, an overlapping pattern with the fibers from upper levels of the cord accumulating in the tract in a dorsomedial direction. 
While still within the inferior cerebellar peduncle, the dorsal spinocerebellar tract gradually spreads out and deviates medialward, at the same time turning dorsalward. It is very difficult, if not impossible, to evaluate any pattern of fiber arrangement from this point. The tract curves sharply dorsalward around the cephalic tip of the dentate nucleus. It appears to the writer that the caudomedial fascicles represent the fibers arising from the higher levels of the cord but no clear conclusion can be drawn.

The final distribution of the dorsal spinocerebellar tract in the cerebellum has been studied in Monkey VI which had a complete unilateral destruction of this tract at $\mathrm{C}_{2}$. It reveals that the dorsal spinocerebellar tract projects to all subdivisions of the vermis, except for lobules I, VII, X and the ventral portion of lobule IX. Lobules II and III receive the greatest contribution; progressive diminution in the number of fibers reaching lobules IV, V and VI, respectively, is evident, with only a small amount of degenerated fibers present in lobule VI. Projection of the dorsal spinocerebellar tract to the posterior vermis is less significant in number of fibers than that to the anterior vermis. The ventral part of lobule VIII serves as the main termination of the fibers in the posterior lobe, with a few fibers in the dorsal parts of lobules VIII and IX.

The dorsal spinocerebellar tract has a bilateral termination with the crossing approximately in a $1: 2$ proportion. The crossing occurs in the central white matter of the cerebellum. All of the dorsal spinocerebellar fibers are confined to the vermis with the exception of a few scattered fibers extending into the closely adjoining hemisphere of the anterior lobe; the contralateral distribution shows less lateral extent. These conclusions are drawn from the data obtained in all the cases.

\section{The ventral spinocerebellar tract}

The course, the fiber arrangement and the termination of the ventral spinocerebellar tract have been studied in Marchi series obtained from 5 experimental animals (Monkeys II, 
III, IV, V and VII). Six lesions were produced surgically in the cord at the levels $\mathrm{S}_{1}, \mathrm{~L}_{2}, \mathrm{~T}_{10}, \mathrm{C}_{8}$, and $\mathrm{C}_{2}$, with a duplication of the experiment at $\mathrm{C}_{2}$. Two lesions at $\mathrm{S}_{1}$ and $\mathrm{C}_{2}$ were made in Monkey III but on different sides of the cord. Both the ventral and the dorsal spinocerebellar tracts on the same side were involved in all lesions except for the lesion at $\mathbf{S}_{1}$.

Monkey VII, with a complete degeneration of the ventral spinocerebellar tract at $\mathrm{L}_{2}$, has been used for the description of the course of this tract in the cord. The ventral spinocerebellar fibers occupy the ventrolateral region of the cord, with a densely packed, comet-shaped area in its most dorsolateral part. A broader ventromedial portion contains diffuse, degenerated fibers, which, presumably, belong partly to the lateral spinothalamic tract. The dorsal limit of the ventral spinocerebellar tract is approximately $1 \mathrm{~mm}$ below the level of the central canal and it apparently does not change in its position through the cord. The degenerated fibers in the loosely packed portion of the tract are more thoroughly incorporated in the ventromedial part of the main mass as they are followed farther cephalad. No fibers appear to migrate dorsalward at any level to join the dorsal spinocerebellar tract. The interval between the two degenerated spinocerebellar components persists and is more evident at higher levels.

It is evident from Monkeys III, VII, IV and V, with complete destructions of the ventral spinocerebellar tracts at the levels $S_{1}, L_{2}, T_{10}$ and $C_{2}$, respectively, that the number of degenerated fibers successively increases ventromedially in passing toward the higher levels of the cord. This comparison can be carried out satisfactorily in our material at upper cervical cord levels. In Monkey III, a lesion produced at $\mathbf{S}_{1}$ resulted only in a few degenerated fibers which are diffusely scattered in the dorsolateral part of this tract at such cervical levels. The tract increases in its density as well as in its extent ventromedially at cervical levels following lesions at successively higher levels of the cord. It is corrcluded that the ventral spinocerebellar tract possesses a pattern of fiber arrangement, with fibers from the lower levels lying dorsolaterally in the tract 
and those from higher segments lying more ventromedial to those already in the tract. This pattern again shows a considerable overlap of the fibers from the different levels.

In all cases, the ventral spinocerebellar tract progresses cephalad in the medulla oblongata to occupy an area along the surface of the medulla dorsolateral to the inferior olivary nucleus. Due to a gradual external rotation and shifting of the components of the tract in its course, its more compact dorsolateral portion at lower medulla levels becomes ventral in the tract at mid inferior olivary levels. The loosely arranged fibers are located in the more dorsal part of the tract at this latter level. The degenerated fibers obtained from a complete destruction of the ventral spinocerebellar tract at $\mathrm{L}_{2}$ in Monkey VII are located in a crescentic area in the most ventral part of the tract at mid inferior olivary levels. In Monkey $\mathrm{V}$, where a degeneration in the ventral spinocerebellar tract follows a lesion at $\mathrm{C}_{2}$, the tract occupies a larger area dorsolaterally, extending to the nucleus of the spinal tract of N.V. The lesions in the various monkeys at $\mathrm{C}_{8}, \mathrm{~T}_{10}$ and $\mathrm{S}_{1}$ provide adequate evidence for the conclusion that a topical arrangement of the ventral spinocerebellar fibers is present at the mid inferior olivary level with the fibers from the caudal levels lying ventrally and those from more cephalic levels added successively in a dorsal direction (figs. 17 and 18). A considerable overlap is again to be noted.

At pontine levels, the ventral spinocerebellar tract appears laminated because of the passing through it of the transversely running fibers of the trapezoid body. Just cephalic to the intramedullary course of N.V, the ventral spinocerebellar tract turns dorsally and curves around the lateral side of the brachium conjunctivum. Finally, the tract ascends caudodorsalward along the superomedial aspect of the brachium to enter the cerebellum. Although it is not clearly evidenced, it appears to the writer that the more dorsolateral fascicles of the tract, in the ventral region of the brainstem are those which first begin to curve at more caudal levels and that they constitute the lateral component of the tract as it lies super- 
ficial to the brachinm conjunctivum. The other fascicles turn successively to maintain their arrangement with respect to each other. From this point on, it is impossible to determine certainly any fiber arrangement in the ventral spinocerebellar tract from our series because of the changing of its direction, the compactness of its fibers, and the already overlapping pattern.

Monkey $\mathrm{V}$, with a unilateral, complete destruction of the ventral spinocerebellar tract at $\mathrm{C}_{2}$, and with less degeneration of the dorsal spinocerebellar tract, will serve as an illustration of the distribution of the ventral tract within the cerebellum. The ventral spinocerebellar fibers are found within all subdivisions of the vermis, except for lobules I, VII and X. The greatest number of fibers reaches lobules II and III; a moderately large amount enters lobules IV, V and VI. A comparatively small amount of fibers projects to the vermis of the posterior lobe, with the greatest contribution to the ventral part of lobule VIII. The dorsal part of lobule VIII and both parts of lobule IX receive a fairly small number of fibers. The lateral limit of distribution and the proportion of the crossed and uncrossed terminations appear similar to those given for the dorsal spinocerebellar tract.

\section{The posterior funiculus and the dorsal superficial arcuate fibers}

Concurrent degenerations of the fibers in the posterior funiculus in some of the experiments provide some confirmative results concerning the segmental pattern in this funiculus. The fasciculus gracilis terminates in the nucleus gracilis with a laminar pattern; the most ventrolateral fascicle forms the most ventrolateral lamina in the nuclear gray and the more dorsomedial fascicles constitute more dorsomedial laminae. The oblique lamination is clearly evident at higher levels because of the divergence of the two clavae (fig. 6).

The fasciculus cuneatus also shows an obliquely laminar pattern of fiber arrangement. In Monkey III a few degener- 
ated fibers in this fasciculus constitute a definitely oblique band, which extends cephalad to terminate in the corresponding regions of the nucleus cuneatus and of the lateral cuneate nucleus. The formation of this successive lamination has been observed in Monkey I, which, fortunately, has an unaffected area in the cuneate fasciculus at the mid cervical cord levels. Undoubtedly, the undegenerated area represents the position of the fibers entering the dorsal funiculus at these levels. Caudally, the spared area lies between the degenerated portion of the fasciculus cuneatus dorsomedially and the tip of the dorsal horn ventrally (fig. 4). As it is followed cephalad, the undestroyed area tends to spread ventromedially and forms a thin lamina which is parallel to the ventrolateral extent of the affected component (fig. 5). This evidence reveals the formation of a laminar pattern of the fasciculus cuneatus to which the entering fibers from the higher levels are successively added in ventrolateral direction. In this fasciculus, the segmental pattern seems to show less overlapping than in the spinocerebellar systems. Another fact to be emphasized is that the fasciculus cuneatus ends partly in the nucleus cuneatus and partly in the lateral cuneate nucleus. Approximately the superficial half of the fasciculus projects to the lateral cuneate nucleus and the rest of the fibers terminate in the nucleus cuneatus. These facts support the view that there is a segmental pattern in the dorsal funiculus and in its terminations (Ferraro and Barrera, '35a and b).

The dorsal superficial arcuate fibers have been studied in Monkey VIII with destructions of the lateral cuneate nucleus, parts of its associated nuclei and portions of the dorsal spinocerebellar tract. These arcuate fibers enter the medial aspect of the inferior cerebellar peduncle and are collected mainly in the dorsal superficial part of this peduncle. The nucleus cuneatus apparently contributes a very few fibers to the inferior peduncle (fig. 20). No degenerated, myelinated fibers can be traced to the inferior peduncle as examined in Monkey $\mathrm{V}$ with the lesion in the clava. There is little possibility that any significant number of the degenerated fibers here de- 
scribed due to the effects of the needle tract through the lateral reticular nucleus, the olivocerebellar connections and the nucleus of the spinal tract of N.V.

The external cuneate nucleus receives fibers from the fasciculus cuneatus, which conveys impulses from the upper part of the body. In turn, the external cuneate nucleus projects, through the dorsal superficial arcuate fibers, to the cerebellum. So the dorsal superficial arcuate system serves for projection of impulses from the upper part of the body on the cerebellum. These arcuate fibers are located in the dorsal superficial part of the inferior peduncle (fig. 19), being added to that portion of the dorsal spinocerebellar tract, which serves upper body levels. The cerebellar distribution of the dorsal superficial arcuate fibers alone cannot be determined with certainty since degenerated fibers of the dorsal spinocerebellar tract are also present. However, the majority of the arcuate fibers appears to project to the vermis of the posterior part of the anterior lobe.

The somatotopical arrangement of the major spinal afferent systems within the cerebellum

Material from Monkeys I to VIII are available in Marchi series for the study, within the cerebellum, of the somatotopical arrangement of the major spinal afferent systems including the dorsal superficial arcuate fibers. Their final distribution is considered as a whole in relation to the levels of the body which they serve. From the evidence presented in a summarized form in table 2, it is evident that the fibers arising from the lower cord segments which serve the lower part of the body project chiefly to the anterior portion of the anterior lobe (lobules II and III) ; the fibers originating in the higher levels of the cord and in the medulla, i.e., serving the upper extremities and the neck, terminate mainly in the posterior part of the anterior lobe (lobules IV and V). As a matter of fact, it appears that there is a great overlapping of topical 


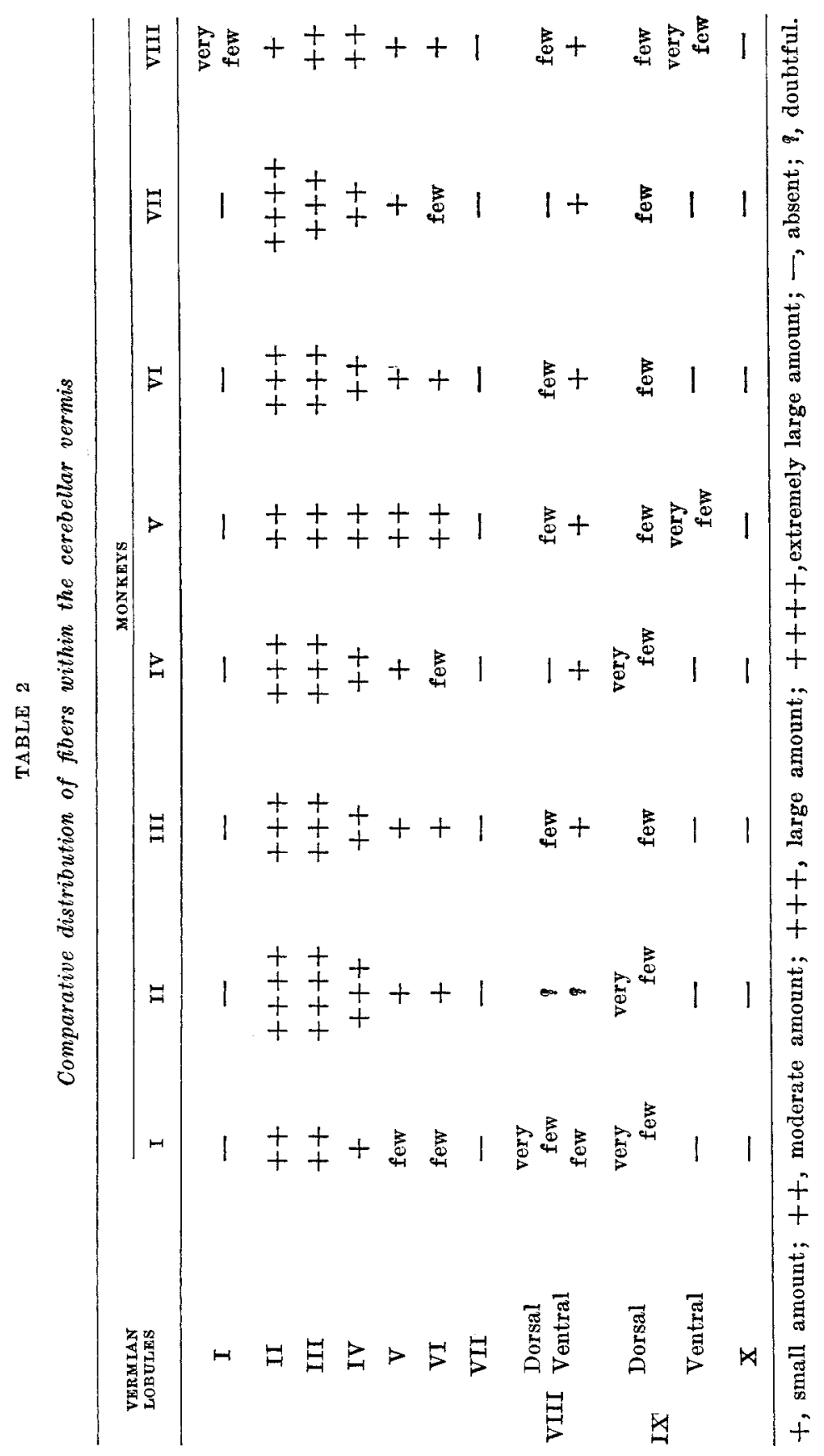


pattern projected by the spinocerebellar systems to the cerebellum, since all of the series showed degeneration throughout the whole cerebellar distribution of these systems. The declive (lobule VI) is associated with the anterior lobe in receiving the projection from these ascending paths to the cerebellum. A comparatively small amount of fibers constitutes another division of the system to reach the pyramis and the uvula. It is not possible from the material at present available to decide whether there is any topical pattern of the fiber distribution in the posterior lobe of the cerebellum.

\section{Cerebellar corticonuclear connections}

There is incomplete physiological evidence, from the stimulation experiments on Monkeys II, IX, X and XI, for a localization pattern of motor responses on the cerebellar cortex. Connections from some of these cortical areas have been traced anatomically to the cerebellar nuclei but it is not possible from the present material to decide whether their termination shows any specific body pattern. Nevertheless, the corticonuclear projection reveals a pattern of termination in relation to the zones of the cerebellar cortex; that is, the vermis projects principally on the nucleus fastigii and the medial part of the hemisphere on the nucleus interpositus; the lateral portion of the hemisphere is connected mainly with the nucleus dentatus. In addition to this mediolateral zonal pattern of projection it is also evident that a rostrocaudal pattern of connections exists. In general, the superior portions of the cerebellum project to the rostral parts of the cerebellar nuclei, the inferior portions to the caudal parts of these nuclei. These patterns, however, are not clear-cut and do not show a point to point localization. In other words, there is a considerable overlapping of the projection so that some of the corticonuclear fibers arising from one side of the vermis are seen to terminate in the opposite nucleus fastigii. 


\section{DISCUSSION}

The topical pattern of fiber arrangement within the dorsal spinocerebellar tract in the macaque spinal cord, as described here, agrees with the results obtained also in macaque monkeys by Yoss ('52). This pattern indicates that fibers arising from the higher levels of the cord are accumulated more ventrally in the tract. Sherrington and Laslett ('03) observed a lateromedial stratification in the dog and this pattern has been confirmed by MacNalty and Horsley ('09) for the cat, the dog and the monkey. Collier and Buzzard ('03) stated that, in man, the longest fibers of the system are in the most dorsal part of the tract as it ascends toward the brain. According to Gardner and Cuneo ('45), a tendency for the dorsal spinocerebellar fibers to shift dorsally during their course was noted in man. Smith ('57a) concluded from human cases that there is a great degree of overlap of the fibers from different segmental levels. Beck, in 1927, could not find any evidence of a lamination pattern within the dorsal spinocerebellar tract in the cat.

The overlapping pattern of localization for the ventral spinocerebellar tract in the spinal cord of the monkey, as observed in this study, confirms Yoss' observations in 1953. This pattern reveals that the longest fibers lie most dorsolaterally and the shorter fibers are located more ventromedially. Several investigators (Hyndman and Van Epps, '39; Walker, '40; Weaver and Walker, '41; Gardner and Cuneo, '45; and others) have demonstrated a laminated arrangement in the ascending fibers of the anterolateral column of the cord. Certainly many of the degenerated fibers described by them belong to the ventral spinocerebellar system, although they were describing the lateral spinothalamic tract. In this study the ventral spinocerebellar fibers are recognized by their greater size and their position which is more superficial than that of the other components of the anterolateral ascending complex (Thiele and Horsley, '01). None of the series studied for this paper revealed any transference of fibers from the ventral spinocerebellar tract to the dorsal spinocerebellar system such as has 
been described by Schäfer and Bruce ('07), Bruce ('10) and Smith ('57a and b).

At present the writer cannot find any record available in the literature concerning the segmental pattern of the spinocerebellar systems in the brainstem. It is concluded from the present study that, within the dorsal spinocerebellar tract, an accumulation of fibers from successively higher levels occurs in a lateromedial direction at caudal medulla levels and in a ventrolateral-dorsomedial direction in the inferior cerebellar peduncle. The dorsal superficial arcuate fibers also join appropriate portions of this segmental pattern in the peduncle. The ventral spinocerebellar tract reveals, at mid inferior olivary levels, an accumulation of fibers ventrodorsally. There is, certainly, a considerable degree of overlap in these patterns.

The termination of the dorsal spinocerebellar tract within the vermis of the anterior lobe and within the declive, as described in this dissertation, agrees in general with the results obtained by almost all authors (Bruce, 1898; MacNalty and Horsley, '09; Beck, '27; Brodal and Jansen, '41; Anderson, '43; Whitlock, '52; Yoss, '52; Jansen and Brodal, '58; and others). MacNalty and Horsley and Yoss did not find fibers to the lingula in the monkey. This is the case also in the present series except for one monkey with a very few fibers reaching the lingula. A few fibers were traced to the tuber and nodulus by MacNalty and Horsley ('09), Beck ('27), Brodal and Jansen ('41). Anderson ('43), Yoss ('52), and the present writer could not follow the dorsal spinocerebellar fibers to these lobules.

The cerebellar distribution of the ventral spinocerebellar fibers, as here described, is not in agreement with the observations of many investigators (Mott, 1892; Bruce, 1898; MacNalty and Horsley, '09; Horrax, '15; Beck, '27; Chang and Ruch, '49; and others), who have considered that these fibers project to the anterior lobe of the cerebellum only. The present observations do confirm the work of Anderson ('43) and of Yoss ('53), who demonstrated that the vermis of the anterior 
lobe and the pyramis, the uvula and the declive received contributions from the ventral spinocerebellar tract.

The somatotopical arrangement of the spinocerebellar systems and of the dorsal superficial arcuate fibers within the cerebellum was shown to be in a rostrocaudal direction in the vermis of the anterior lobe and the declive. The more cephalic portion serves the more caudal segments of the body, i.e., fibers from the lower extremities terminate, for the most part, in the central lobule and the anterior part of the culmen. The dorsal superficial arcuate fibers appear to be a supplementary system to the dorsal spinocerebellar tract for the upper part of the body, according to their origin, course and termination. However, this is a widely overlapping pattern. The work of Chang and Ruch ('49) on the spider monkey and that of Yoss ('52) on the macaque monkey also suggest that such a pattern exists. On the contrary, many physiological findings (Snider and Stowell, '42, '44a and b; Grundfest and Campbell, '42; Snider, '50; Carrea and Grundfest, '54; and others) reveal a more distinct localization pattern on the cerebellum with a more lateral spread.

The patterns of the cerebellar corticonuclear connections obtained from the present study are in essential agreement with those observed by Jansen and Brodal ('40, '42), who found that there is a rostrocaudal as well as a mediolateral zonal pattern of projection. However, the pattern revealed in our material is widely overlapping. The observations of several authors (Probst, '02; Clarke and Horsley, '05; Bender, '32; and others) also suggest a mediolateral zonal pattern of projection. The corticonuclear projection from the cortex of the vermis to the nucleus fastigii has both crossed and uncrossed fibers, as maintained by Probst ('02) and as indicated in our experiments. However, Mussen ('29) and Rasmussen ('33) had stated that these corticonuclear fibers are crossed connections from the vermis to the fastigial nucleus and Jansen and Brodal ('40) and Hohman ('29) had regarded them as ipsilateral. 


\section{SUMMARY}

1. This experimental study is concerned with the anatomy of the dorsal and the ventral spinocerebellar tracts, the dorsal superficial arcuate fibers and the cerebellar corticonuclear connections in Macaca mulatta.

2. The course, the fiber arrangement and the termination of these systems were determined.

3. The somatotopical patterns of these spinal afferent fibers within the spinal cord, the brainstem, the inferior cerebellar peduncle and the cerebellum were considered.

4. The observations also include the projection pattern of the cerebellar corticonuclear connections.

5. The arrangements and the terminations of the posterior funicular fibers were emphasized.

\section{ACKNOWLEDGMENTS}

The technical help for this research was, in large part, provided by the Walter-Hill Medical Research Fund and the monkeys were a gift of the Parke Davis Pharmaceutical Company. The author wishes to express his sincere appreciation. To Professor Elizabeth C. Crosby, the author wishes to express his decpest gratitude for her invaluable advice. The author is indebted to Mr. James Turley, Mr. Paul Czöny, Miss Hope Powell-Tuck, and the late Mr. George Smith for their technical assistance and also to Dr. Edward Lauer and Miss Donna Crook for their help with preparation of the illustrations. To all others in the Laboratory of Comparative Neurology, who in one way or another assisted in the present work, the author wishes to extend his acknowledgements.

\section{LITERATURE CITED}

ANDERson, R. F. 1943 Cerebellar distribution of the dorsal and ventral spinocerebellar tracts in the white rat. J. Comp. Neur., $79: 415-432$.

BECK, G. M. 1927 The cerebellar termination of the spinocerebellar fibers of the lower lumbar and sacral segments of the cat. Brain, 50:60-98.

BENDER, L. 1932 Corticofugal and association fibers arising from the cortex of the vermis of the cerebellum. Areh. Neurol. Psyehiat., 28: 1-25. 
Brodal, A., AND J. JANSEN 1941 Beitrag zur Kenntnis der spinocerebellaren Bahnen beim Menschen. Anat. Anz, 91: 185-195.

Bruce, A. N. 1898 Note on the upper termination of the dircet and ascending antero-lateral tracts. Brain, $81: 374-382$.

1910 The tract of Gowers. Quart. J. Exp. Physiol, 3: 391-407.

CARREA, R., AND H. GRUNDFEst 1954 Electrophysiological studies of the ascending inflows into the cerebellum. J. Neurophysiol., 17: 208-238.

Chang, H., AND T. C. RUCH 1949 The projection of the caudal segments of the spinal cord to the lingula in the spider monkey. J. Anat., 83: $303-307$.

Collier, J., AND E. F. Buzzard 1903 The degenerations resulting from lesions of posterior nerve roots and from transverse lesions of the spinal cord in man. A study of 20 cases. Brain, 26: 559-591.

Clarke, R. H., and V. Horsley 1905 On the intrinsie fibers of the cerebellum, its nuelei and its efferent tracts. Ibia., $88: 13-29$.

Ferraro, A., AND S. E. Barrera 1935a The nuclei of the posterior funiculi in Macacus rhesus. An anatomical and experimental investigation. Arch. Neur. Psychiat., 33: 262-275.

1935 b Posterior column fibers and their termination in Macacus rhesus. J. Comp. Neur., 6: : 507-530.

GARDNER, E., NND H. M. CUNEO 1945 Lateral spinothalamic tract and associated tracts in man. Areh. Neur. Psychiat., 53: 423-430.

GrundFest, H., AND B. CAMPBel 1942 Origin, conduction and termination of impulses in the dorsal spinocerebellar tract of eats. J. Neurophysiol., 5: $275-294$.

HoHMAN, L. B. 1929 The efferent connections of the cerebellar cortex; investigations based upon experimental extirpations in eat. Res. Publ. Assn. Nerv. Ment. Dis., 6: $445-460$.

Horrax, G. 1915 A study of the afferent fibers of the body wall and of the hind legs to the cerebellum of the dog by the method of degeneration. Anat. Rec., 9: 307-321.

Hyndman, O. R., And C. VAn EPPs 1939 Possibility of differential section of the spinothalamic tract. A clinical and histologic study. Areh. Surg., 38: 1036-1053.

JANSEN, J., AND A. Brodar, 1940 Exporimental studies on the intrinsic fibers of the cerebellum. II. The corticonuclear projection. J. Comp. Neur., 78 : $267-321$.

1942 Experimental studies on the intrinsic fibers of the cerebellum. The corticonuclear projection in the rabbit and the monkey (Macacus rhesus). Norske Vid. Akad. I, Math. Naturv. Kl, Avh. nr. 3 : 1-50.

1954 Aspects of Cerebellar Anatomy. Johan Grundt Tanum, Oslo, $423 \mathrm{pp}$.

1958 Das Kleinhirn. Band 4, Teil 8, Handbuch der mikroskopischen Anatomic des Menschen. W. v. Möllendorf and W. Bargmann, eds. Springer-Verlag, Berlin, Göttingen and Heidelberg. 323 pp.

IARseli, O. 1951 Anatomy of the nervous system, 2nd ed. Appleton-Century. Crofts, Ine., New York. 
MacNalty, S., ANd V. Horstex 1909 On the cervical spinobulbar and spinocerebellar tracts and on the question of topographical representation in the cerebellum. Brain, 3\%: 237-255.

Moтr, F. W. 1892 Ascending degenerations resulting from lesions of the spinal cord in monkeys. Ibid., 15: 215-229.

Mussen, A. T. 1929 Experimental investigations on the cerebellum. Res. Publ. Nerv. Ment. Dis., 6: 381-423.

Probst, M. 1902 Zur Anatomie und Physiologie des Kleinhirns. Arch. Psychiat., 35: $692-777$.

Rasmussen, A. T. 1933 Origin and course of the fasciculus uncinatus (Russell) in the cat, with observations on other fiber tracts arising from the cerebellar nuclei. J. Comp. Neur., 5\%: 165-197.

SCHÄFER, E. A., AND A. M. BRUCE 1907 The eerebellar tracts of the spinal cord. J. Physiol., 35: xlix.

Sherrington, C. S., And E. E. LasletT 1903 Remarks on the dorsal spinocerebellar tract. Ibid., 29: 188-194.

Smith, M. C. $1957 \mathrm{a}$ The anatomy of the spinocerebellar fibers in man. I. The course of the fibers in the spinal cord and brain stem. J. Comp. Neur., 108: 285-352.

$1957 \mathrm{~b}$ Observations on the topography of the lateral column of the human cervical spinal cord. Brain, 80: 263-272.

SNIDER, R. S. 1950 Recent contributions to the anatomy and physiology of the cerebellum. Arch. Neur. Psychiat., 64: 196-219.

SNIDER, R. S., AND A. STOWELL 1942 Evidence of tactile sensibility in the cerebellum of the cat. Fed. Proc., 1: 82.

1944a Electroanatomical studies on a tactile system in the cerebellum of monkey (Macaca mulatta). Anat. Rec., 88: 457 .

$1944 \mathrm{~b}$ Receiving areas of the tactile, auditory, and visual system in the cerebelium. J. Neurophysiol., $7: 331-357$.

SWANK, R. L., AND H. A. DAVENPORT 1935 Chlorate-osmic-formalin method for staining degenerating myelin. Stain Tech., 10: 87-90.

THIEle, F. H., AND V. HoRsLey 1901 A study of the degenerations observed in the central nervous system in a case of fracture dislocation of the spine. Brain, Q4: 519-531.

Walker, A. E. 1940 The spinothalamic tract in man. Areh. Neurol. Psychiat., $43: 284-298$.

Whaver, T. A., AND A. E. WALKER 1941 Topical arrangement within the spinothalamie tract of the monkey. Ibid., $46: 877-883$.

WhiтLock, D. G. 1952 A neurohtstological and neurophysiological investigation of the afferent fiber tracts of the avian cerebellum. J. Comp. Neur., $9 \%$ : $567-636$.

Yoss, R, E, 1952 Studies of the spinal cord. I. Topographic localization within the dorsal spinocerebellar tract in Macaca mulatta. J. Comp. Neur., 97 : $5-20$.

1953 Studies of the spinal cord. IT. Topographic localization within the ventral spinocerebellar tract in the macaque. Ibid., 99:613-638. 


\section{Abbreviations to plates}

Ace. parafloc., accessory parafloceulus $\mathrm{CN}$, cuneate nucleus

Dorsal parafloc., dorsal paraflocculus DSCT, dorsal spinocerebellar tract FC, fasciculus cuneatus $\mathrm{FG}$, fasciculus gracilis

IAF, internal arcuate fibers ICP, inferior cerebellar peduncle
LCN, lateral cuneate nucleus LCST, lateral corticospinal tract LSTT, lateral spinothalamie tract ML, medial lemniseus NG, nucleus gracilis STT, spinotectal tract VSCT, ventral spinocerebellar tract Vent. parafloc., ventral parafloceulus

PLATE 1

EXPLANATION OF FIGURES

1 Diagrammatic representation of the superior surface of the macaque cerebellum showing its subdivisions and the locations of the cortical lesions in Monkey IX (coarse stippled) and in Monkey XI (horizontally striped). $\times 2.5$.

2 Diagram of the inferior surface of the macaque eerebellum showing its subdivisions and the locations of the cortical lesions in Monkeys II (fine stippled), $X$ (checkered) and XI (horizontally striped). $\times 2.5$.

3 Diagrams of the macaque cerebellar vermis in the midsagittal plane to illustrate its subdivisions and some of the relations between lobules I and II. $\times 2.5$. 


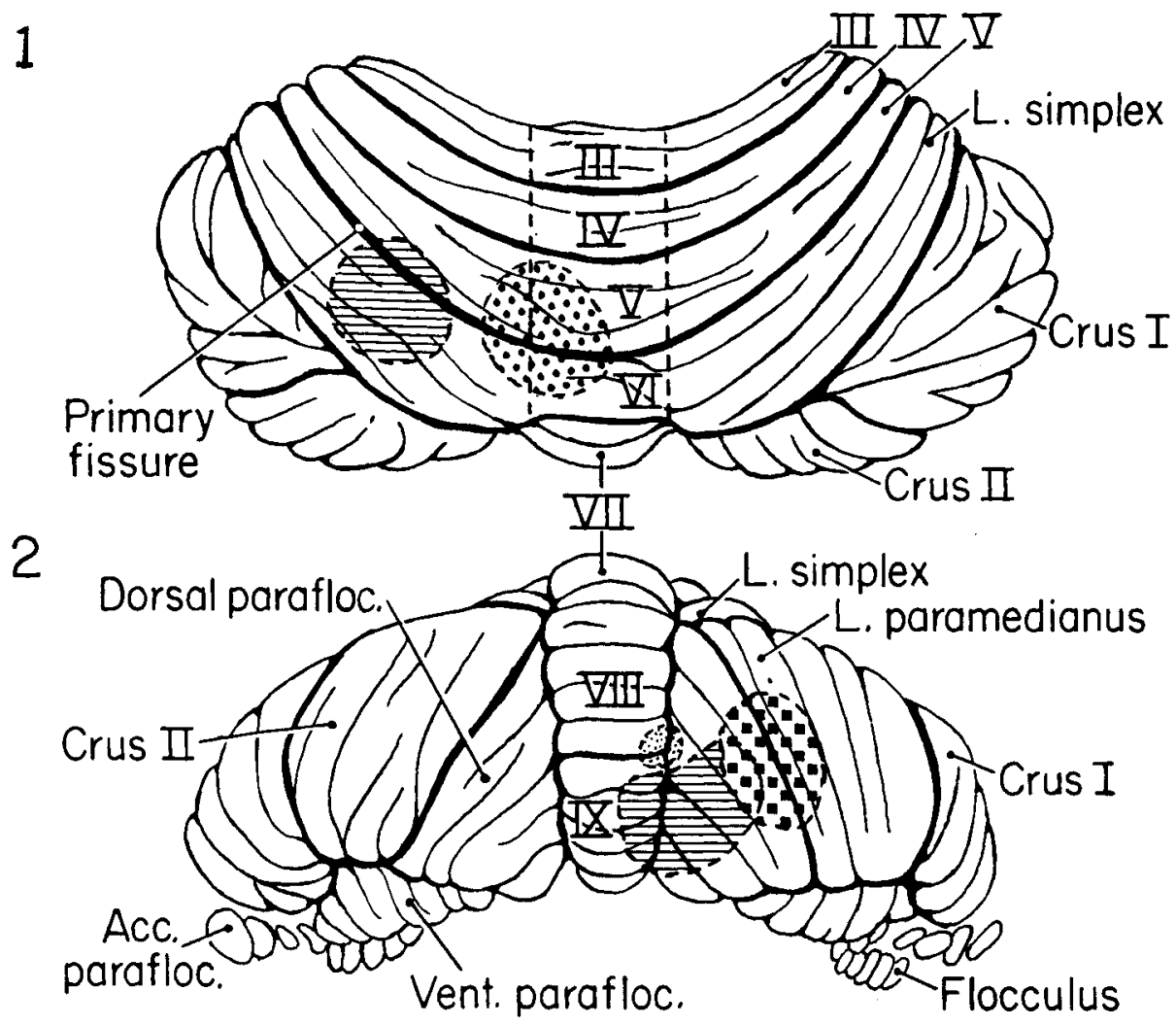

3
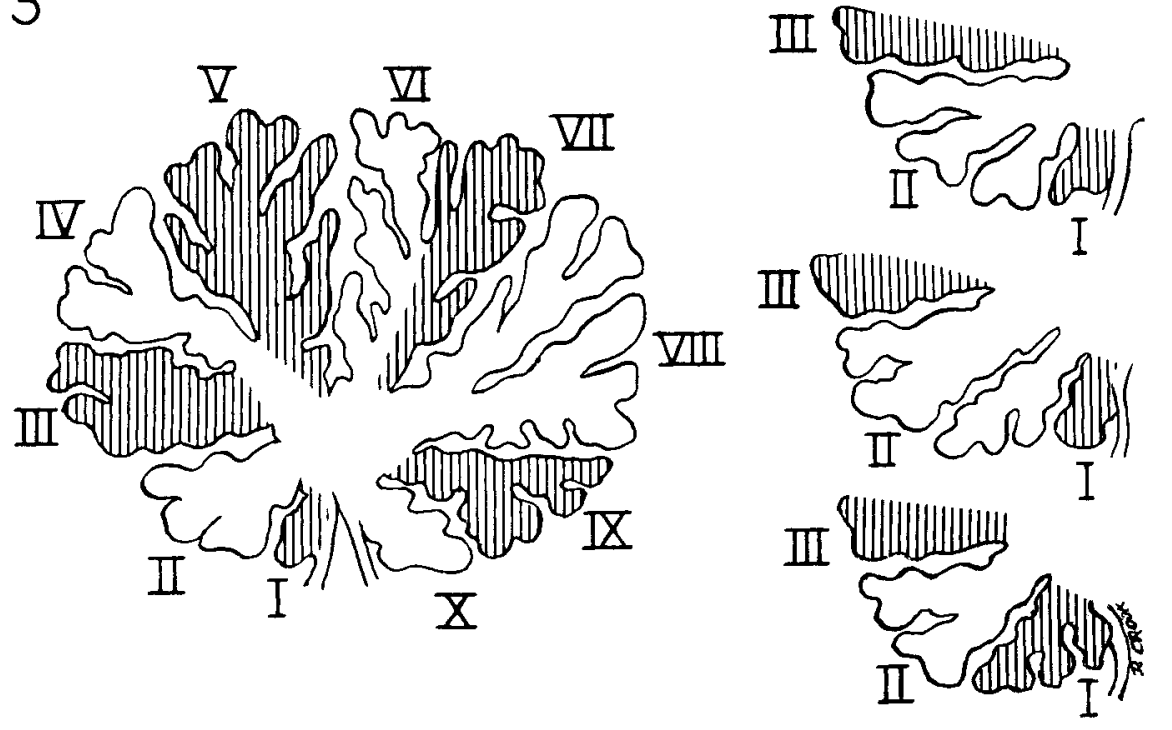
PLATE 2

\section{EXPLANATION OF FIGURES}

4, 5 Monkey I. Transverse sections of the spinal cord at $\mathrm{C}_{5}$ and $\mathrm{C}_{4}$. Arrows indicate the unaffected eomponents of the left fasciculus cuneatus. Notice the ventromedial extension of the spared area at $\mathrm{C}_{4}$. Marchi stain. $\times 9$.

6 Monkey I. Transverse section of the medulla at its caudal levels showing the terminations of the posterior funicular fibers. The fasciculus gracilis ends in the nucleus gracilis (A). The deeper portion of the fasciculus cuneatus terminates within the nucleus cuneatus (B) and the superficial portion of this fasciculus (C) continues forward to end in the lateral cuneate nucleus (shown in fig. 8). Marehi stain. $\times 9$.

7 Monkey I. Transverse section of $\mathrm{C}_{1}$ to illustrate the relations between the dorsal spinocerebellar tract and the lateral corticospinal tract. Marchi stain. $\times 9$.

8 Monkey I. Transverse seetion of the medulla at the caudal level of the inferior olivary nucleus. Note the termination of the superficial part of the fasciculus cuneatus within the lateral cuneate nucleus. Note also the dorsal shift of the dorsal spinocerebellar fibers as they enter the inferior cerebellar peduncle. Marehi stain. $\times 9$.

9 Monkey I. Transverse section through the medulla at the middle of the inferior olive to show the sequence of shifting of the dorsal spinocerebellar fibers to enter the inferior cerebellar peduncle. The most medially placed fascicles in the lower medulla are the last group to shift dorsalward (arrow) in order to oceupy the dorsal superficial portion of the peduncle. Marchi stain. $\times 9$. 
THE SPINOOEREBELLAR SYSTEMS

PLATE 2

BHUKET VACHANANDA
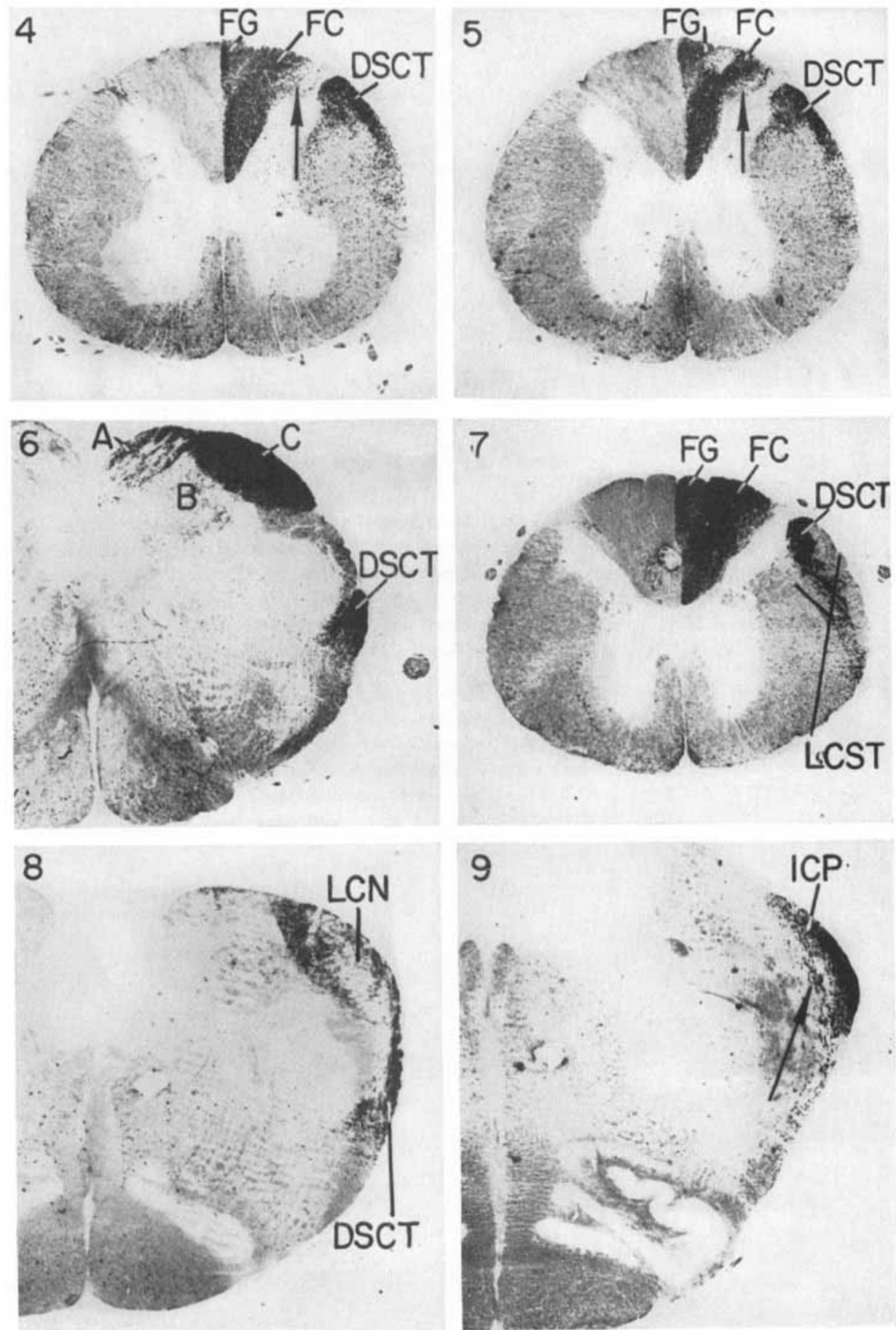


\section{PLATE 3}

EXPLANATION OF FIGURES

10, 11 Monkey II. Transverse sections through the medulla at the middle and at the caudal levels of the inferior olive, respectively, to show the degeneration of the left spinocerebellar tracts following the lesion at $\mathbf{C}_{2}$. Note the dorsal shift of the dorsal spinocerebellar fibers to enter the inferior cerebellar peduncle. The lateral cuneate nucleus (fig. 11) receives degenerated fibers from the superficial portion of the fasciculus cuneatus. Marchi stain. $\times 9$.

12 Monkey IV. Transverse seetions through the medulla and the spinal cord: a, at $\mathrm{C}_{1} ; \mathrm{b}$, at the level of the motor decussation; $\mathrm{c}$, at a level just eaudal to the inferior olive; and d, at the mid inferior olivary level to show the degeneration of the right spinocerebellar tracts after the cord lesion at $\mathrm{T}_{10}$. Observe the dorsal shift of the dorsal spinocerebellar fibers at different levels. Also notice the concentration of degenerated fibers in a particular area of each tract. Marchi stain. $\times 9$. 
THE SPINOCEREBELLAR SYSTEMS
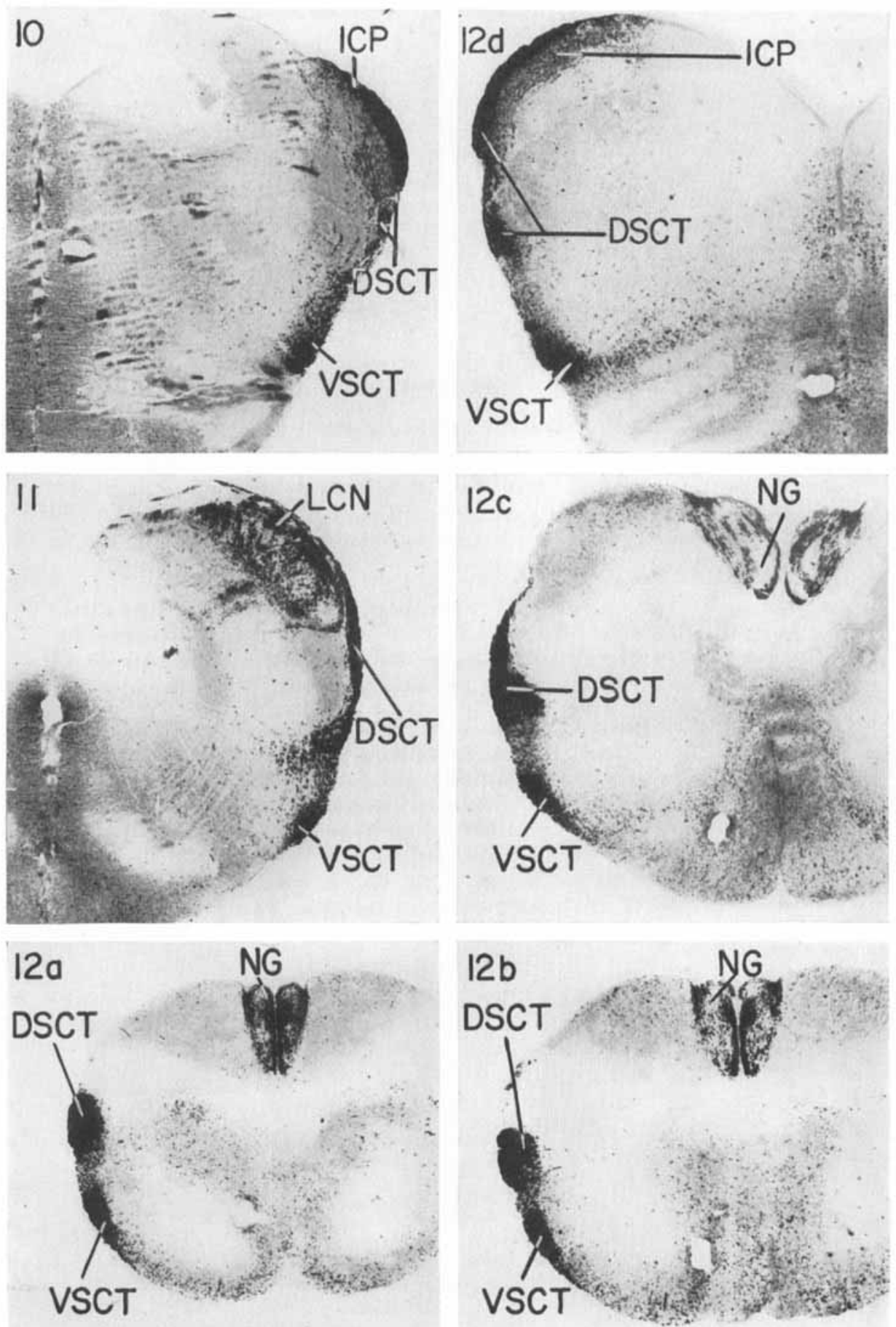


\section{PLATE 4}

FXPLANATION OF FIGURES

13 Monkey III. Transverse section of the medulla at the level of the motor decussation showing the degeneration of the left spinocerebellar tracts and of the right ventral spinocerebellar tract following the cord lesions at $\mathrm{O}_{8}$ and $\mathrm{S}_{1}$, respectively. Marchi stain. $\times 9$.

14 Monkey $V$. Transverse sections of the medulla: a, at the mid inferior olivary level; b, at the level of the motor decussation, to show the degenerations pro-duced by a left ventrolateral cordotomy at $\mathrm{C}_{2}$. Note the relations between the ventral spinocerebellar tract and its associated tracts. Marchi stain. $\times 9$.

15 Monkey VI. Transverse sections of the medulla and the spinal cord: a, at the mid inferior olivary level; $b$, at the level of the motor decussation and $c$, at $\mathrm{C}_{1}$, to show the degeneration following a dorsal spinocerebellar tractotomy at $\mathrm{C}_{2}$. Notice the relations of the dorsal spinocerebellar tract at upper cord levels and also note the dorsal slift of the fibers of this tract as they ascend. rostrad. The most medially placed faseicles in the lower medulla are the last group to shift dorsalward (arrow in fig. 15a) in order to occupy the dorsal superficial part of the inferior cerebellar peduncle. Marchi stain. $\times 9$. 

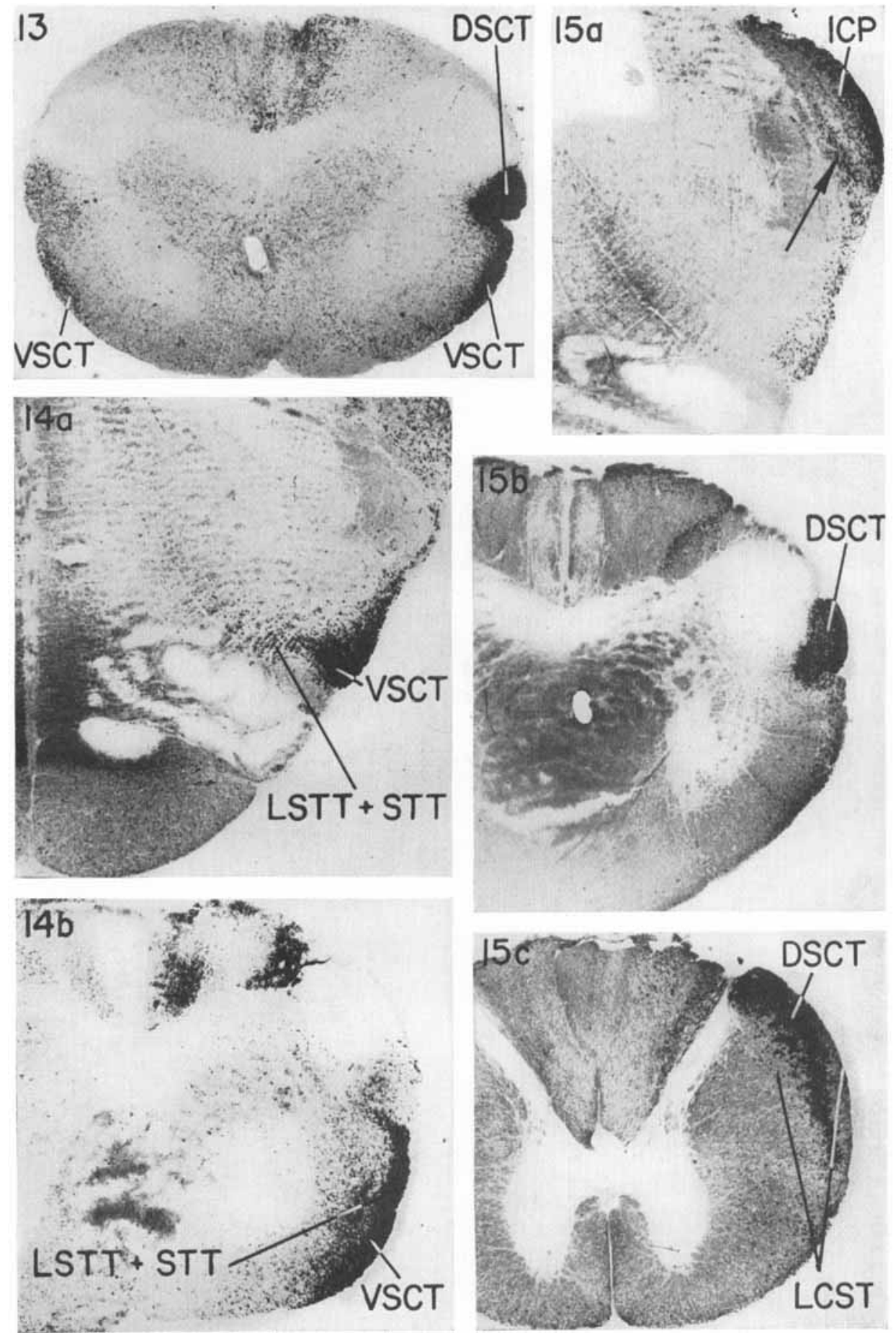


\section{PLATE 5}

FXPLANATION OF FIGURE

16 Monkey VII. Transverse sections of the medulla and the spinal cord at the levels indicated to illustrate the degeneration in both the dorsal and the ventral spinocerebellar tracts produced by a right ventrolateral cordotomy at $\mathrm{L}_{\mathrm{y}}$. Note the successive changes in fiber arrangements in both tracts as they ascend cephalad. Marchi stain. $\times 9$. 


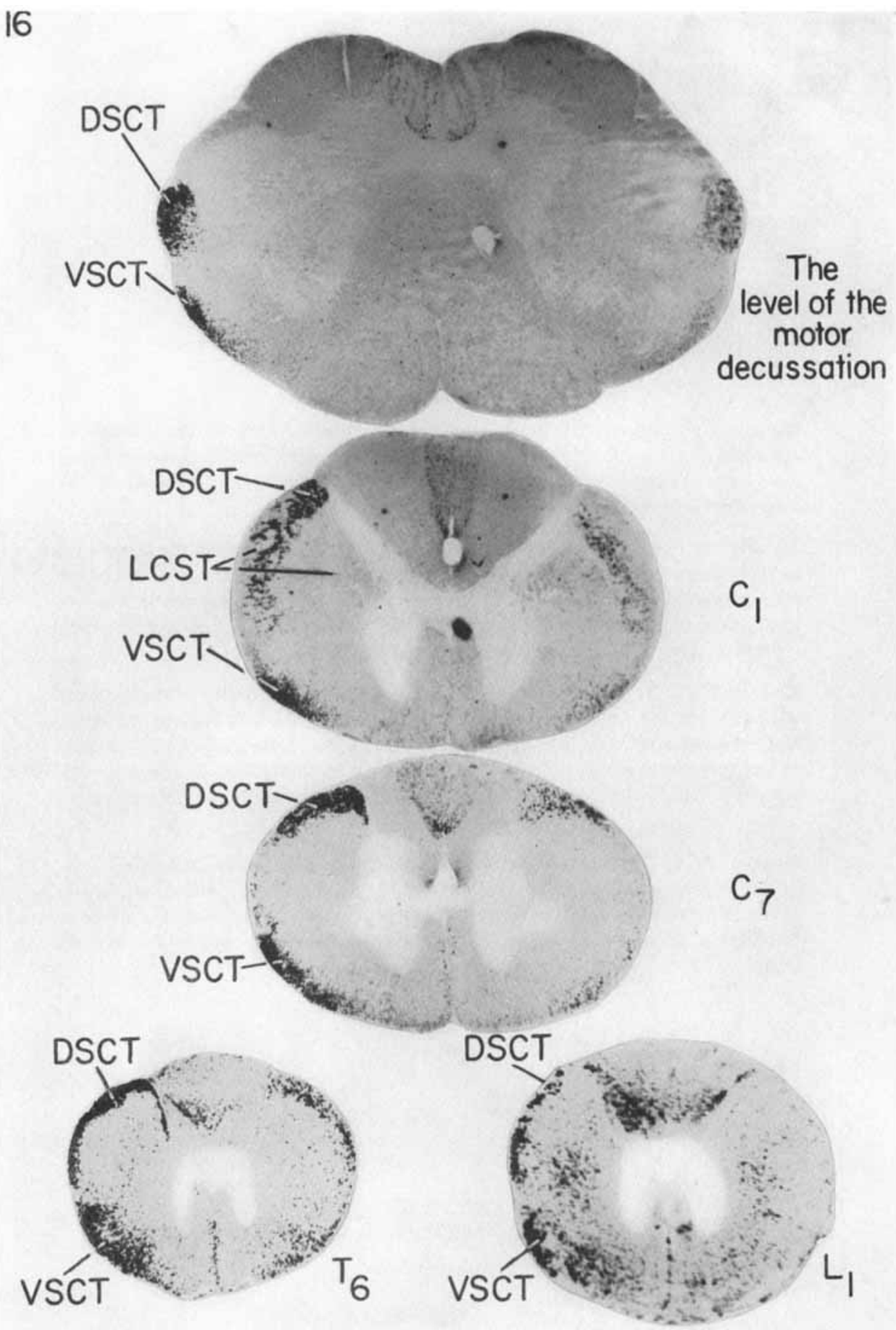




\section{PLAT'E 6}

\section{EXPLANATION OH F'IGURES}

17 Monkey VII. Transverse section through the inferior olive of the medulla to show the degeneration of the right dorsal and the right ventral spinocerebellar tracts following a cord lesion on the right at $\mathrm{L}_{2}$. Note the locations of the degenerated fibers in each tract. Marchi stain. $\times 9$.

18 Monkey II. Transverse section of the medulla, approximately at the same level as that shown in figure 17, showing the degenerated left ventral spinocerebellar tract produced by a cord lesion on the left at $\mathrm{C}_{2}$. Note the increase in number of degencrated fibers dorsally in this tract as a result of the more rostral lesion (compare with fig. 17). Marchi stain. $\times 9$.

19 Monkey VIII. Transverse section of the medulla at the middle of the inferior olive to show the degeneration following a lesion in the left cuneate tubercle. Note the accumulation of degenerated fibers in the dorsal superficial portion of the inferior cerebellar peduncle. The arrow indicates the direction of the internal arcuate fibers which arise from the cuneate nucleus. Marchi stain. $\times 9$.

20 Monkey VIII. Transverse section through the inferior olive, a few sections caudal to that presented in figure 19. Note the degenerations following a lesion in the left cuneate tubercle. A very few degenerated fibers (arrows), possibly from the nucleus euneatus, reach the inferior cerebellar peduncle. Marchi stain. $\times 12$. 
BHUKET FACHANANDA
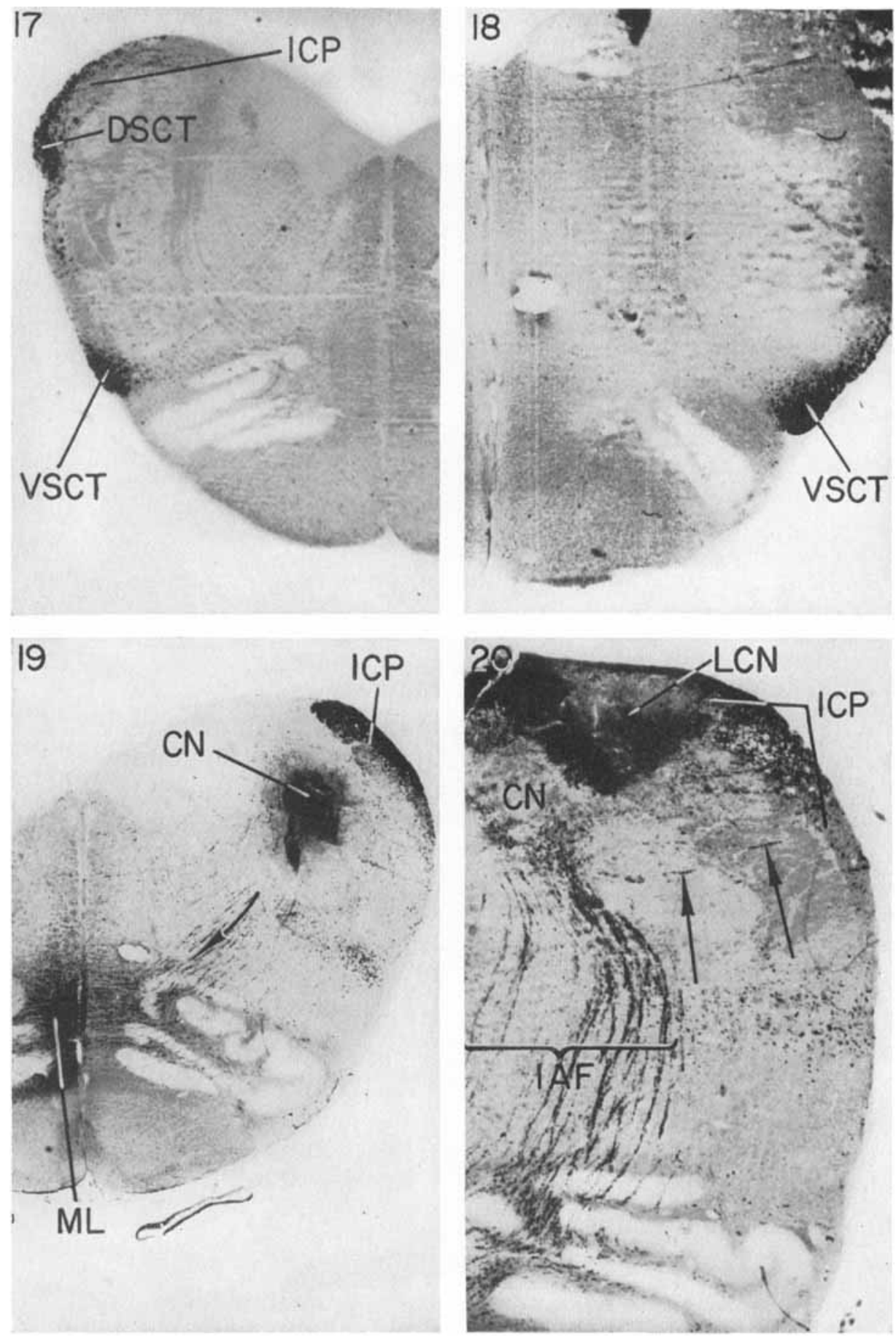